\title{
DIVISIÓN DEL DESLIZAMIENTO TECTÓNICO Y TRANSTENSIÓN EN EL MACIZO DEL VOLCÁN POÁS (COSTA RICA), BASADO EN ESTUDIOS NEOTECTÓNICOS Y DE SISMICIDAD HISTÓRICA
}

\section{TECTONIC SLIP PARTITIONING AND TRANSTENSION IN THE POÁS VOLCANIC MASSIF (COSTA RICA), BASED ON NEOTECTONIC AND HISTORICAL SEISMICITY STUDIES}

\author{
Walter Montero ${ }^{1,2 *}$, Gerardo J. Soto ${ }^{1,3,4}$, Guillermo E. Alvarado ${ }^{1,3}$ \& Wilfredo Rojas ${ }^{1}$ \\ ${ }^{1}$ Escuela Centroamericana de Geología, Universidad de Costa Rica, Apdo. \\ 214-2060, Ciudad Universitaria Rodrigo Facio, Costa Rica \\ ${ }^{2}$ Centro de Investigaciones en Ciencias Geológicas (CICG), Universidad de Costa Rica \\ ${ }^{3}$ Instituto Costarricense de Electricidad, Apdo. 10032-1000, San José, Costa Rica \\ ${ }^{4}$ Terra Cognita Consultores S.A. \\ *Autor para contacto: wmontero@geologia.ucr.ac.cr
}

(Recibido: 25/08/2009; aceptado: 08/11/2010)

\begin{abstract}
A review of previous literature and new morphotectonic, structural, and seismological interpretations have allowed us to characterize the neotectonics of Poás volcanic massif. As a result of this research, we extend the Ángel fault trace southward of its previous defined trace and suggest its northwest continuation. We also define the northwest-trending, predominantly dextral-slip Sabanilla fault. These two faults and the Carbonera and Viejo-Aguas Zarcas faults, define a predominantly dextral fault system, here named as Ángel-Sabanilla-Aguas Zarcas. This system originates an associated transtensive structure that includes the Poás summit faults, the Sabana Redonda pyroclastic cones, and the eruptive centers of Botos, Poás and Von Frantzius. This fault system and the thrust fault-propagation folds of Alajuela and San Miguel define the tectonic system of Poás volcano massif. Slip partitioning explains the relationship between the Alajuela and San Miguel thrust faults and the predominantly dextral slip Ángel, Sabanilla, Carbonera and Viejo-Aguas Zarcas faults. According to such new tectonic interpretations, the source of the historical earthquakes of 1772, 1888, 1911, 1912 and 1955 is reinterpreted and a rupture model is proposed, including the recent Cinchona earthquake of January 8, 2009. Accordingly, fault segments without recent ruptures define the regions with the highest seismic hazard of the Poás massif region.

Keywords: Neotectonics, morphotectonics, structural geology, seismicity, Poás volcano, Costa Rica.
\end{abstract}


RESUMEN: Una revisión de la literatura existente y nuevas interpretaciones morfotectónicas, estructurales y sismológicas permiten caracterizar la neotectónica del macizo del volcán Poás. Como resultado de esa investigación, se extiende al sur el trazo de la falla Ángel y se sugiere su extensión al noroeste. Asimismo, se propone una nueva falla de rumbo noroeste y movimiento predominante dextral, que se denomina Sabanilla. Las anteriores dos fallas junto con las fallas Carbonera y Viejo-Aguas Zarcas, conforman un sistema de falla predominantemente dextral que se denomina Ángel-Sabanilla-Aguas Zarcas, que origina una estructura transtensiva dentro de la cual se ubican las fallas cuspidales del Poás, los conos piroclásticos de Sabana Redonda, y los focos volcánicos de Botos, Poás y Von Frantzius. Este sistema de falla, junto con las fallas Alajuela y San Miguel, caracterizados por sus pliegues asociados con fallas de propagación inversa, definen el sistema tectónico del macizo del Poás. Este arreglo tectónico se explica por la división del deslizamiento entre las fallas inversas San Miguel y Alajuela y las predominantemente dextrales Ángel, Sabanilla, Carbonera y Viejo-Aguas Zarcas. Con base en lo anterior, se reinterpreta la fuente de origen de los terremotos históricos de $1772,1888,1911,1912$ y 1955 y se propone un modelo de rupturas que incluye el reciente terremoto de Cinchona del 8 de enero del 2009, donde se sugieren sectores de falla sin rupturas recientes, con los cuales se asociaría la mayor amenaza sísmica dentro del macizo del Poás.

Palabras clave: Neotectónica, morfotectónica, geología estructural, sismicidad, volcán Poás, Costa Rica.

\section{INTRODUCCIÓN}

El macizo del volcán Poás (Fig. 1), como parte de la actual Cordillera Central, ha crecido como el apilamiento de varias etapas de crecimiento de la cordillera a lo largo de al menos 600 mil años (Soto, 1999; Carr et al., 2007; Denyer \& Alvarado, 2007). Cubre un área aproximada de $300 \mathrm{~km}^{2} \mathrm{y}$ se encuentra limitado en sus faldas sur y norte por las fallas inversas de Alajuela y San Miguel respectivamente (Alvarado et al., 1988; Borgia et al., 1990; Soto, 1999; Arroyo \& Alvarado, 2002), mientras que hacia el este limita con el macizo del Barva y al oeste con el del volcán Viejo-PorvenirPlatanar.

Dentro del macizo Poás se han identificado varias fallas neotectónicas, como son las fallas Carbonera y Ángel (Alvarado et al., 1988; Montero et al., 1998; Soto, 1999). Esta última fue la fuente del terremoto de Cinchona del 8 de enero del $2009\left(M_{w} 6,1\right)$, el cual provocó considerables deslizamientos y daños a la infraestructura (Rojas et al., 2009). El objetivo del presente trabajo es realizar una revisión y actualización de las principales estructuras neotectónicas presentes en el macizo del volcán Poás y los esfuerzos tectónicos que controlan los focos de actividad volcánica.

Para cumplir con este objetivo, se han revisado varios de los informes de circulación limitada realizados principalmente para los proyectos hidroeléctricos del Instituto Costarricense de

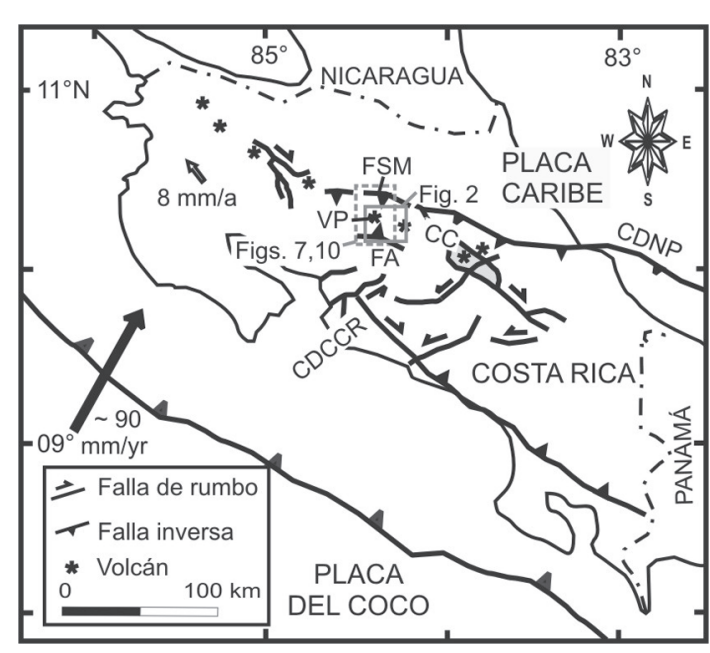

Fig. 1: Tectónica regional. CC es la Cordillera Central, VP es el volcán Poás, FSM y FA son las fallas San Miguel y Alajuela respectivamente. CDCCR y CDNP son respectivamente el Cinturón Deformado del Centro de Costa Rica y el Cinturón Deformado del Norte de Panamá. La flecha rellena en negro muestra la velocidad relativa Coco-Caribe a una escala que es la mitad de la escala de la flecha sin rellenar que corresponde con la velocidad obtenida por Norabuena et al. (2004) para el bloque Nicoya. Los rectángulos muestran las áreas que cubren las figuras 2 (gris sólido) y 7 y 10 (gris a trazos). La zona definida en gris es la cuenca de tracción Turrialba - Irazú (Montero, 2003).

Electricidad (ICE). Además, se incluyen nuevos resultados obtenidos de la reinterpretación tectónica y el trabajo de campo, como corolario de los estudios realizados a partir de la ocurrencia del terremoto de Cinchona mencionado. 


\section{MARCO TECTÓNICO}

Costa Rica se encuentra localizada en el borde suroeste de la zona de subducción entre las placas Coco y Caribe (Fig. 1). La Cordillera Central, dentro de la cual se ubica el macizo del volcán Poás, se localiza a lo largo del arco interno en la parte central del país. Esta región se localiza dentro de un cinturón de fallas activas que ha sido denominado el Cinturón Deformado del Centro de Costa Rica (CDCCR: Marshall et al., 2000; Montero, 2001). En este sistema de fallas predominan las fallas sinestrales de rumbo este a noreste y las dextrales de rumbo noroeste. Uno de los aspectos relevantes que se analizaron es si las estructuras neotectónicas del macizo del volcán Poás son controladas por los esfuerzos tectónicos regionales, por los procesos volcánicos o por una interacción entre ambos.

\section{NEOTECTÓNICA DEL MACIZO DEL VOLCÁN POÁS}

Las principales fallas que se han referido en la literatura geológica que se ubican dentro del macizo del volcán Poás son Alajuela, San Miguel, Carbonera y Ángel (Alvarado et al., 1988; Borgia et al., 1990; Montero et al., 1998; Soto, 1999; Figs. 1, 2). Además, en este trabajo se define la falla Sabanilla y se revisan varias fallas localizadas sobre el flanco este y sur-suroeste del volcán Poás incluyendo la falla Viejo-Aguas Zarcas, que aunque se encuentra ubicada dentro del macizo volcánico Viejo-Porvenir-Platanar, debe ser considerada en la interpretación tectónica de las estructuras existentes dentro del macizo del volcán Poás. A continuación se describen las anteriores fallas de sur a norte y de oeste a este.

\section{Falla de Alajuela}

El escarpe de Alajuela es una geoforma conspicua conocida desde mediados del siglo XIX (Fig. 2). Se relaciona con un pliegue asociado con una falla de propagación inversa que tiene un rumbo variable entre E-W y WNW, que se extiende por unos $20 \mathrm{~km}$ desde la ciudad de Grecia al oeste, hasta la ciudad de Santa Bárbara al este.

\section{Investigaciones previas}

La falla de Alajuela fue originalmente interpretada por Attwood (1882) como una terraza de lago y por Sapper (1905) como una terraza de río. Bergoeing \& Malavassi (1982) la interpretaron como un alineamiento de frentes de coladas de lavas. Como estructura tectónica fue interpretada inicialmente como una falla normal (p.e. Romanes, 1912; Schaufelberger, 1935; Williams, 1952; Bohnenberger \& Madrigal, 1968; Dóndoli \& Chaves, 1968). Más recientemente, mediante estudios geomorfológicos, cartografiado geológico de detalle e investigaciones geofísicas, Borgia et al. (1990) interpretaron que el escarpe y las lomas adyacentes se deben a un pliegue relacionado con una falla de propagación inversa. De allí en adelante aparece en múltiples trabajos como una falla inversa (v.gr.: Montero, 2001; Denyer et al., 2003).

\section{Geomorfología}

La principal geoforma que caracteriza la falla de Alajuela es su escarpe frontal facetado al sur, con uno o dos quiebres de pendiente, el cual continúa al norte con una zona de levantamiento en forma de lomas, limitadas al norte por contraescarpes de suave inclinación que miran al norte (Figs. 2, 3). Los levantamientos tienen un relieve topográfico entre 150-200 m, un ancho entre 200-400 m, y forman un patrón festoneado cuya topografía muestra frecuentes saltos en escalera al cruzar los ríos (Borgia et al., 1990). El escarpe había sido dibujado de manera rectilínea en varios mapas anteriores a 1990, aunque en realidad, se curva en varios segmentos (Borgia et al., 1990), y atenúa su expresión morfológica hacia el occidente y el oriente. Bohnenberger (1968) había expresado que lavas del Barva provocan que el escarpe esté enmascarado cerca de Santa Bárbara. 


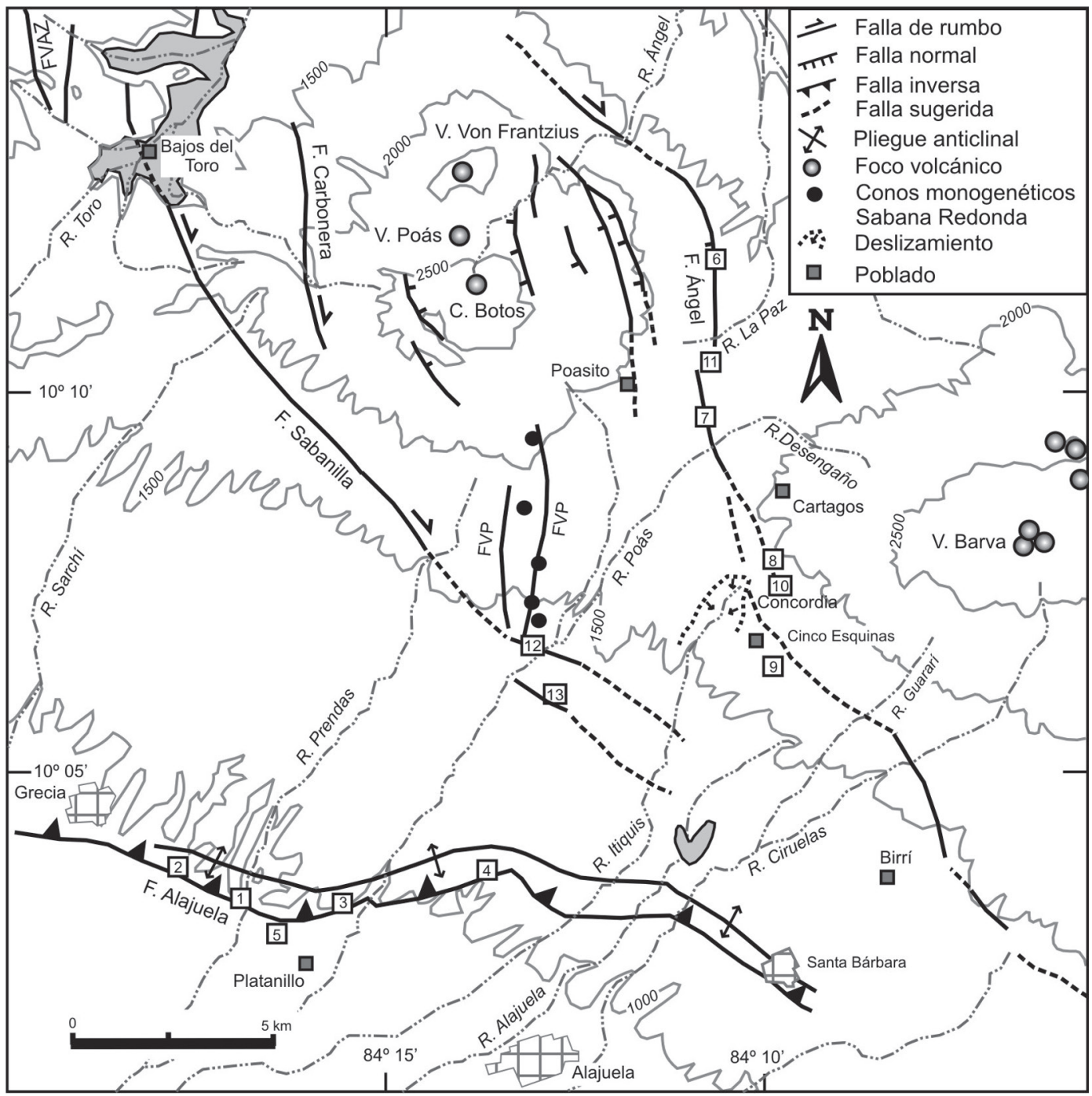

Fig. 2: Neotectónica de la parte central y sur del macizo del volcán Poás. Los cuadrados con números indican la ubicación de sitios referidos en el texto. Las áreas en gris son zonas de depositación aluvial-lahárica definidas en el texto. FVAZ es la falla ViejoAguas Zarcas. FVP es la fractura volcanotectónica del Poás (Gazel \& Ruiz, 2005).

En la parte trasera de las lomas antiformas se han desarrollado represamientos y cuencas por el plegamiento y levantamiento de la Falla de Alajuela. Ejemplos son los depósitos aluvionales y de flujos de detritos (debris flows) que se encuentran al noreste de las lomas, a los lados de los cauces de los ríos Ciruelas, Itiquís y Alajuela (Fig. 2).

\section{Geología estructural}

Los diversos afloramientos y tajos observados en el campo, que cortan transversalmente la estructura del escarpe, el levantamiento y el contraescarpe muestran que estas geoformas corresponden con un plegamiento anticlinal de los depósitos volcánicos y sedimentarios (lacustres 
$\mathrm{y}$ aluviales), lo cual fue asociado por Borgia et al. (1990) con una falla de propagación inversa (Fig. 4). De esta manera, el escarpe frontal facetado al sur corresponde con un escarpe de flanco de pliegue. La zona de levantamiento corresponde con un anticlinal con doble superficie axial, siendo el contraescarpe, el flanco trasero del pliegue. Estafalla en la propuesta de Borgia et al. (1990) no aflora y es, por tanto, una falla ciega. La estructura anterior fue descrita principalmente con base en las observaciones geológicas realizadas en el tajo del río Prendas (sitio 1 en Fig. 2; Fig. 4) y en el levantamiento geológico realizado en el río Itiquís y apoyadas por datos geofísicos (gravimétricos y magnéticos). En visitas realizadas a otros tajos y cortes se ha confirmado la anterior estructura (sitios 2, 3 y 4 en Fig. 2). La altura del escarpe es mayor entre los ríos Itiquís y Prendas. La altura del escarpe y el tamaño del levantamiento (debido al plegamiento) están en relación directa con el deslizamiento acumulado en la falla (ver Suppe, 1985; Borgia et al., 1990).

Sin embargo, Soto (2005) con base en observaciones realizadas en el Tajo Las Américas (sitio 4 en Fig. 2), considera que la falla de Alajuela aflora donde forma una cataclastita (mesobrecha a brecha, sensu Twiss \& Moores, 1992, p. 53), con clastos de decimétricos a métricos de ignimbrita en medio de una matriz arcillosa-arenosa de tamaños variables (Fig. 5). Las tobas e ignimbritas de Tiribí están plegadas en posiciones verticales y hasta ligeramente volcadas en el frente de explotación, a diferencia de los costados, donde están prácticamente horizontales. El contacto entre estos paquetes de rocas lo interpretó a través de una falla subvertical. La presencia de la cataclastita (de granulometría decimétrica a métrica, con espesor decamétrico) le indicó que la falla como tal, sí aflora en ese sector. Si este fuera el caso, muy probablemente la falla se propagó a lo largo de la superficie axial anticlinal o sinclinal adyacente al encontrarse con una formación con una alta resistencia a la flexión. En el caso de la falla de Alajuela, esto pudo haber ocurrido cuando el frente de deslizamiento principal alcanzó las ignimbritas de la Formación Tiribí.

En el río Itiquís, en el flanco delantero del pliegue, las ignimbritas están buzantes $50^{\circ}$ al SW, y tras el pliegue, en el río Ciruelas, los buzamientos de la ignimbrita son suaves $\left(10^{\circ}-13^{\circ}\right)$ hacia el E y NE, lo cual evidencia bien la geometría del pliegue, tal como la habían dibujado Borgia et al. (1990).

Una variación de la interpretación tectónica de Borgia et al. (1990) es la sugerencia de que la falla se ha propagado más al sur del escarpe de Alajuela. Efectivamente, entre los resultados encontrados en la Campaña Geológica 2004 se sostiene que, geomorfológicamente se puede identificar un sinclinal y un anticlinal al sur del escarpe

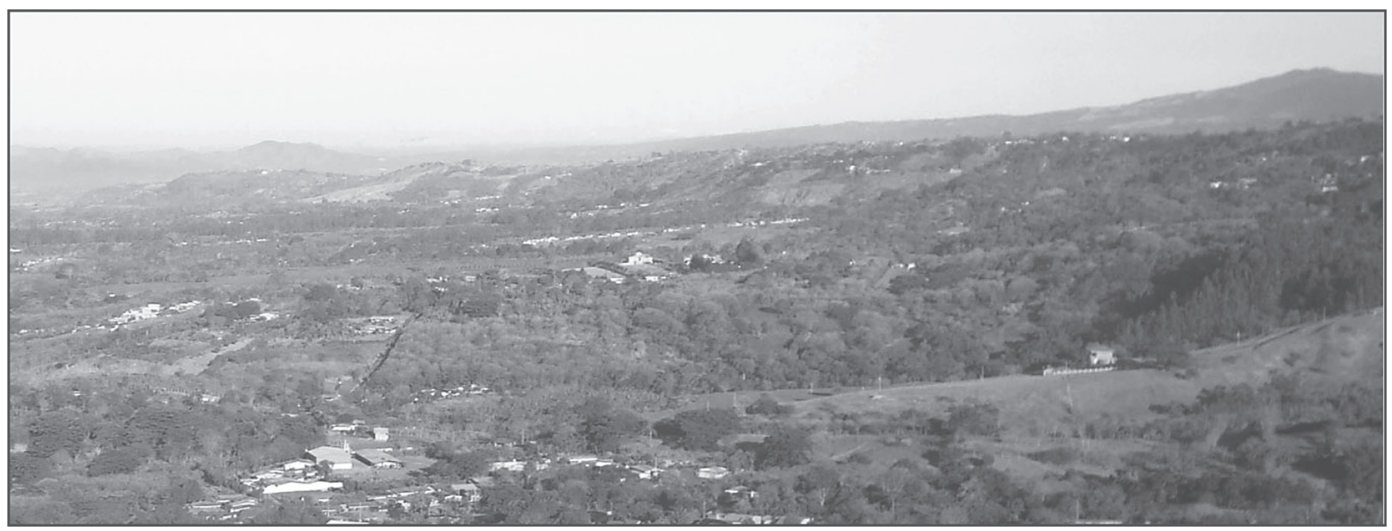

Fig. 3: Vista al WNW del escarpe de Alajuela, desde su extremo oriental. 


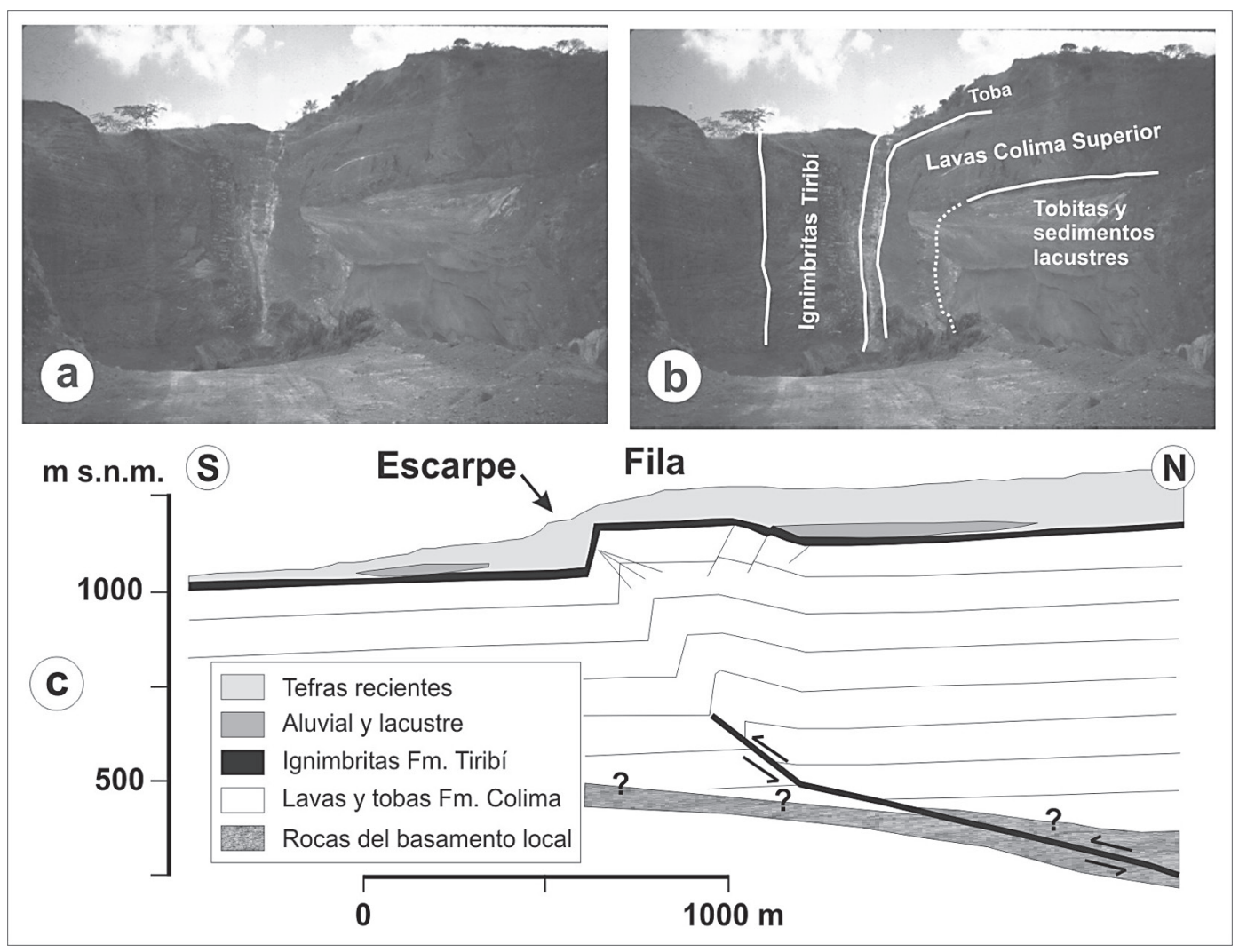

Fig. 4: Estructura de la falla y pliegue de Alajuela. a: El tajo (a) del río Prendas, hoy abandonado y cubierto de bosque secundario, al suroeste del Parque Recreativo Los Chorros (sitio 1 en Fig. 2) con el limbo del pliegue y estratigrafía simplificada (b). La interpretación regional de la falla y pliegue según Borgia et al (1990) se presenta en c.

de la falla de Alajuela, que pueden estar asociados con la propagación hacia el frente de la estructura principal (Fig. 6). Dicha estructura se observa en un valle ubicado al sur del escarpe donde se encuentra la Finca Chilamate, en el poblado de Platanillo (sitio 5 en Fig. 2). No obstante, no hay criterios estratigráficos ni estructurales visibles para afirmarlo con total certeza, puesto que los espesos depósitos de epiclastos ocultan la posible estructura y relaciones de estos pliegues.

\section{Edad}

Con seguridad es $<322 \mathrm{ka}$, en tanto que afectan a las ignimbritas de la Formación Tiribí de esa edad (según Pérez et al., 2006), y del orden de $>40$ $\mathrm{ka}$, puesto que varias lavas jóvenes del macizo
Barva, presumiblemente con edades de alrededor de 40 ka ó más (Arredondo \& Soto, 2006), se desbordan sobre el escarpe. Fallamiento secundario relacionado con la falla Alajuela se ha encontrado cortando depósitos aluviales recientes, lo que puede suponer una edad del Pleistoceno terminal al Holoceno (Borgia et al., 1990).

\section{Falla Ángel}

Es una falla segmentada de rumbo variable entre $\mathrm{N} 70^{\circ} \mathrm{W}$ y N-S, que se extiende por más de $20 \mathrm{~km}$, según el nuevo trazo propuesto en este trabajo (Fig. 2). Al norte de Birrí se inicia con rumbo $\mathrm{N} 25^{\circ} \mathrm{W}$. Continúa con un trazo segmentado con rumbo entre $\mathrm{N} 70^{\circ} \mathrm{W}$ y $\mathrm{N} 30^{\circ} \mathrm{W}$ sobre la falda oeste del volcán Barva. Un nuevo segmento de rumbo 

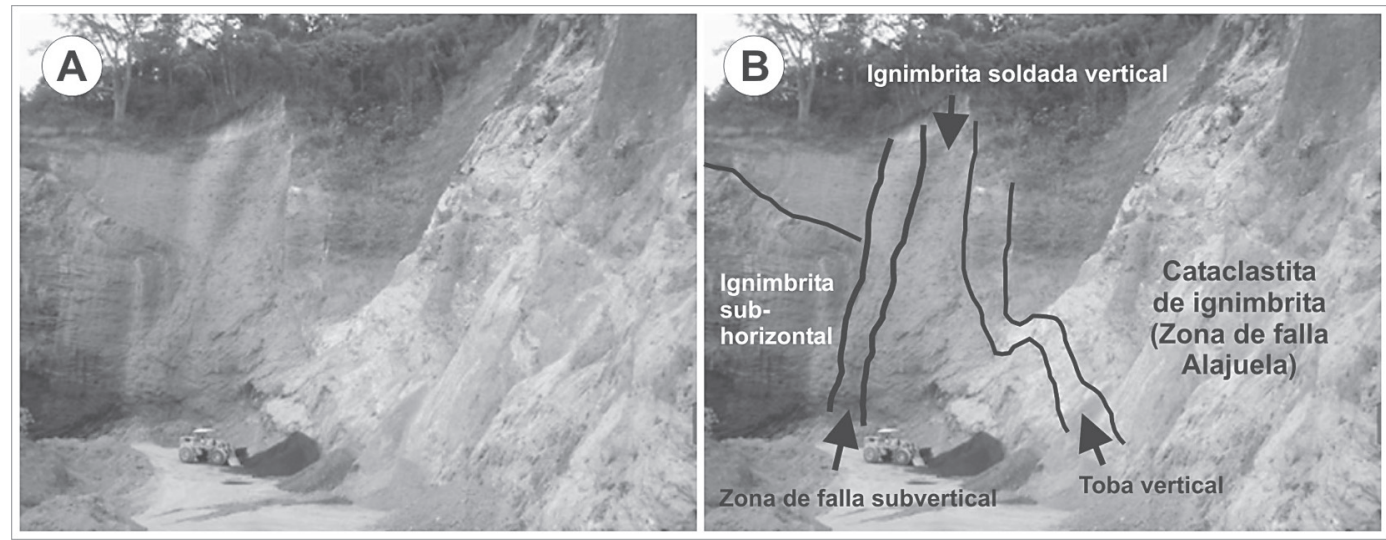

Fig. 5: Estructuras visibles en el frente de explotación del Tajo Las Américas (sitio 4 en Fig. 2). A: Panorámica. B: Interpretación: estratos verticales de la Formación Tiribí, la zona de falla es definida por una cataclastita, y una falla subvertical secundaria.

N-S se localiza sobre la falda este del volcán Poás y termina con un rumbo $\mathrm{N} 50^{\circ} \mathrm{W}$ al noreste del volcán Poás. Arroyo \& Alvarado (2002) proponen una serie de lineamientos de rumbo noroeste y movimiento predominantemente dextral ubicados sobre el flanco nor-noroeste del volcán Poás. Uno de estos, denominado falla Venecia por Barquero et al. (2007), podría considerarse como la continuación de la falla Ángel hacia el noroeste (Fig. 7). Esta falla sugerida parece terminar cerca de la falla San Miguel al noroeste (ver adelante). Al sur, la falla Ángel se une con la falla Sabanilla (ver adelante) y luego ambas continúan como una sola falla hacia el sureste.

\section{Investigaciones previas}

Fue descrita originalmente por Alvarado et al. (1988). Estos autores la muestran con un rumbo $\mathrm{N} 30^{\circ} \mathrm{W}$, cuya prolongación hacia el sureste de Varablanca, estaría cubierta por cenizas holocenas. Soto (1999) la remapea con base en fotografías aéreas y sugiere un trazo de falla que difiere en cierto grado del originalmente descrito por Alvarado et al. (1988) y Barquero (1995). Una nueva revisión detallada de las fotografías aéreas de esta zona con control parcial de campo, ha permitido redefinir el trazo y extensión de esta falla (Fig. 2).

\section{Geomorfología}

En su trazo al noreste del volcán Poás, tiene un rumbo $\mathrm{N} 50^{\circ} \mathrm{W}$, el cual tiene prominencia que varía entre fuerte y débil. En este sector muestra claros desvíos derechos de divisorias y quebradas, entre los cuales el más sugestivo es el del río Ángel, que sería de unos 650 m (Fig. 2). Sin embargo, este desvío podría ser parcialmente resultado de la presencia de alguna litología altamente resistente a la erosión. Además, se observan divisorias angostadas, cambios de pendientes, sillas de falla y drenajes adaptados. Sobre la falda este del volcán Poás, la falla cambia de rumbo hacia el norte. En esta zona, la falla muestra contraescarpes facetados al oeste, valles lineales, lagunas

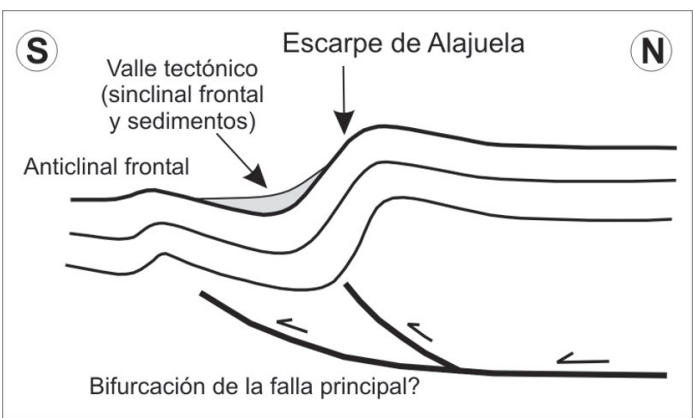

Fig. 6: Modelo que esquematiza la posible génesis del valle tectónico y de los pliegues frontales posiblemente asociados con el escarpe de Alajuela. 


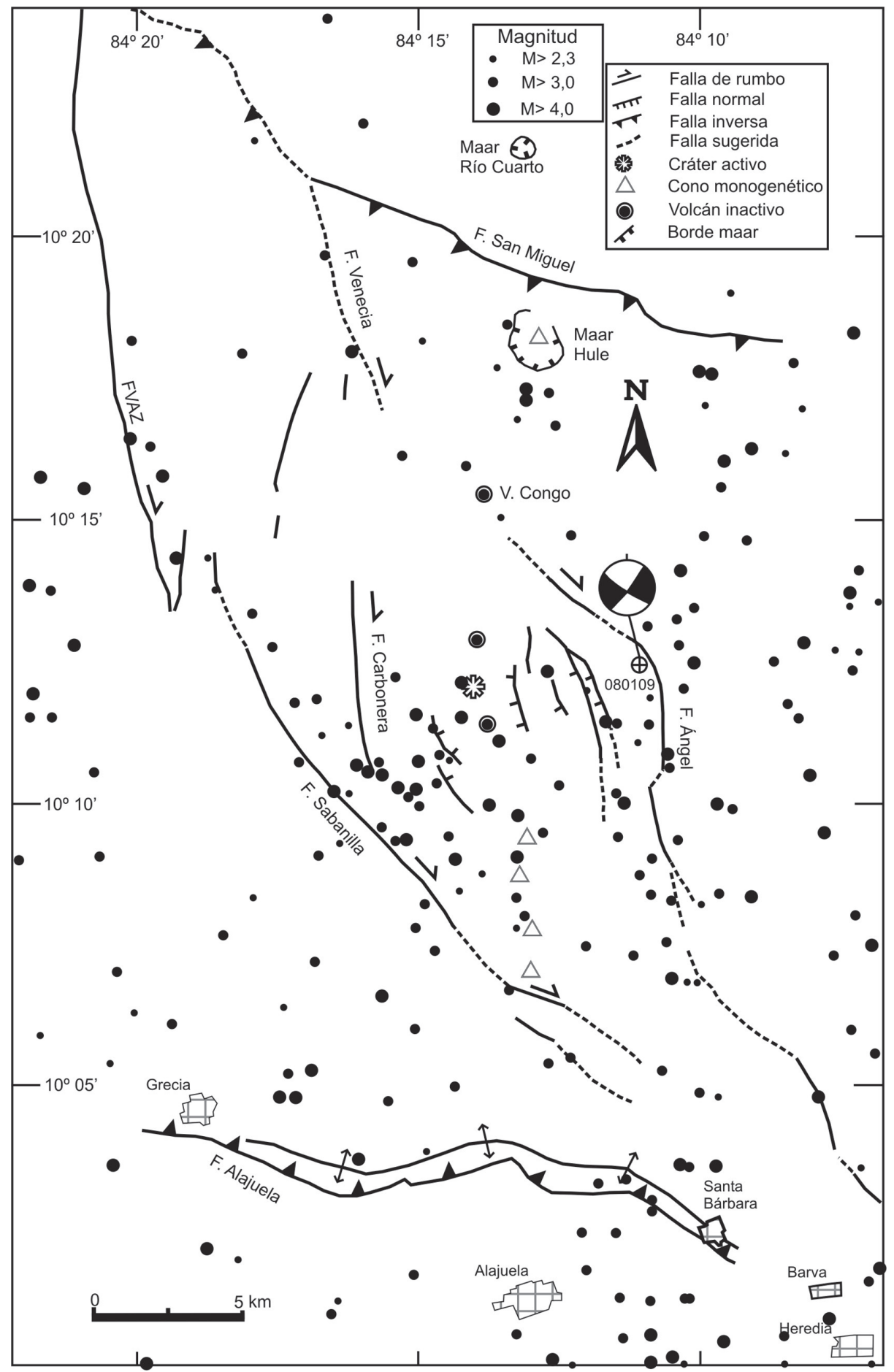

Fig. 7: Relación entre fallas y sismicidad obtenida de la Red Sismológica Nacional (RSN: UCR-ICE), período 1987-2004, M 22,3, profundidad $\leq 20 \mathrm{~km}$, errores en la horizontal y vertical $\leq 10 \mathrm{~km}$. FVAZ es la falla Viejo - Aguas Zarcas. Se incluye el epicentro del terremoto de Cinchona del 8 de enero del $2009\left(M_{w}\right.$ 6,2) y su mecanismo focal obtenido por Harvard. 
de falla y sillas de falla como las observadas en la finca Montaña Azul (sitio 6 en Fig. 2; Fig. 8).

$\mathrm{Al}$ cruzar al sur el río La Paz, se presenta un relevo derecho y se entra al sector ubicado sobre la falda oeste del volcán Barva (Fig. 2). En esta zona se observan divisorias y drenajes desviados dextralmente, como el del río Desengaño. Al estesureste de Poasito (sitio 7 en Fig. 2), se observaron cuatro charcas pantanosas alineadas con la traza de la falla, que se asocian con paleodeslizamientos.

Al sur de la localidad de Cartagos, el trazo se vuelve menos prominente. Sin embargo, entrando en un camino pavimentado dentro de la finca $\mathrm{La}$ Condesa (sitio 8 en Fig. 2), se observó a lo largo de la traza de falla, un paleodeslizamiento y un laguito ubicado atrás del material deslizado. Un gran deslizamiento en las nacientes del río Itiquís oscurece su trazo al suroeste de la localidad de Concordia. Más al sureste, entre Cinco Esquinas y Birrí, la falla origina descansos en la topografía y desvíos derechos en quebradas y ríos, como el Guararí y Ciruelas. Al sureste del río Ciruelas origina un contraescarpe y un valle lineal.

\section{Geología estructural}

Durante el trabajo de campo fue posible definir la presencia de la falla en varios afloramientos. Se observó que la falla, al cortar depósitos piroclásticos, origina una zona de falla que puede ser de varias decenas de metros de ancho, debido al bajo grado de consolidación que tienen estos depósitos.

Cerca de Cinco Esquinas, en un tajo abandonado afloran una serie de lavas y depósitos piroclásticos, en los cuales se encontraron varias fallas de rumbo predominante WNW y de alto ángulo cortando ambas secuencias (sitio 9 en Fig. 2). Más al norte, dentro de una finca lechera cercana a Concordia, un corte cercano a la traza de la falla, muestra depósitos piroclásticos cortados por fallas de alto ángulo, de rumbo $\mathrm{N} 60-70^{\circ} \mathrm{E}$ y con separaciones normales, que pueden ser asociados con una zona de distensión a lo largo de la falla (sitio 10 en Fig. 2).

En un corte de camino dentro de la finca La Condesa, en una toba se observó un pliegue de charnela aguda cortado por una falla subvertical de rumbo N-S (sitio 8 en Fig. 2). Unos $50 \mathrm{~m}$ al oeste de donde se ubica la traza principal, una serie de depósitos piroclásticos están cortados por diversas fallas de alto ángulo, rumbo entre ENE y WNW y muestran separaciones normales. Estas fallas se podrían asociar con colapso gravitacional debido a paleodeslizamientos o con distensión local.

Del lado norte de la divisoria continental de aguas, en un afluente del río La Paz (sitio 11 en Fig. 2), se encontró a lo largo de la traza de la falla, un afloramiento de unos $20 \mathrm{~m}$ de ancho, mostrando una secuencia de diversos eventos piroclásticos pobremente consolidados, cortados por fallas de alto ángulo. Las fallas tienen rumbos dominantes entre NNE y ENE. Precisamente en esta zona la falla Ángel tiene un relevo transtensivo.

\section{Estructuras cuspidales del Poás}

Consisten en un conjunto de fallas arqueadas ubicadas cerca de la cúspide del volcán Poás. Las direcciones predominantes son N-S hasta NNWSSE y se localizan sobre los bordes este y oeste del volcán Poás.

\section{Investigaciones previas}

Fueron mapeadas por Thorpe \& Francis (1981) y Prosser \& Carr (1987) como dos calderas en nido, y se mencionan en Brown et al. (1987). Corresponden parcialmente con algunos lineamientos mostrados en Woodward \& Clyde (1993). Alvarado (1989) y Soto (1999) las cartografían como fallas arqueadas. Ambos argumentan con base en trabajos de campo que no hay ignimbritas voluminosas cuyas erupciones puedan haber originado tales calderas.

\section{Geomorfología}

Se caracterizan por mostrar escarpes facetados al este (lado oeste del volcán) y al oeste (lado este del volcán), lo cual sugiere buzamientos de las fallas al oeste y este, respectivamente. En términos generales, se observa que los ríos y quebradas al 


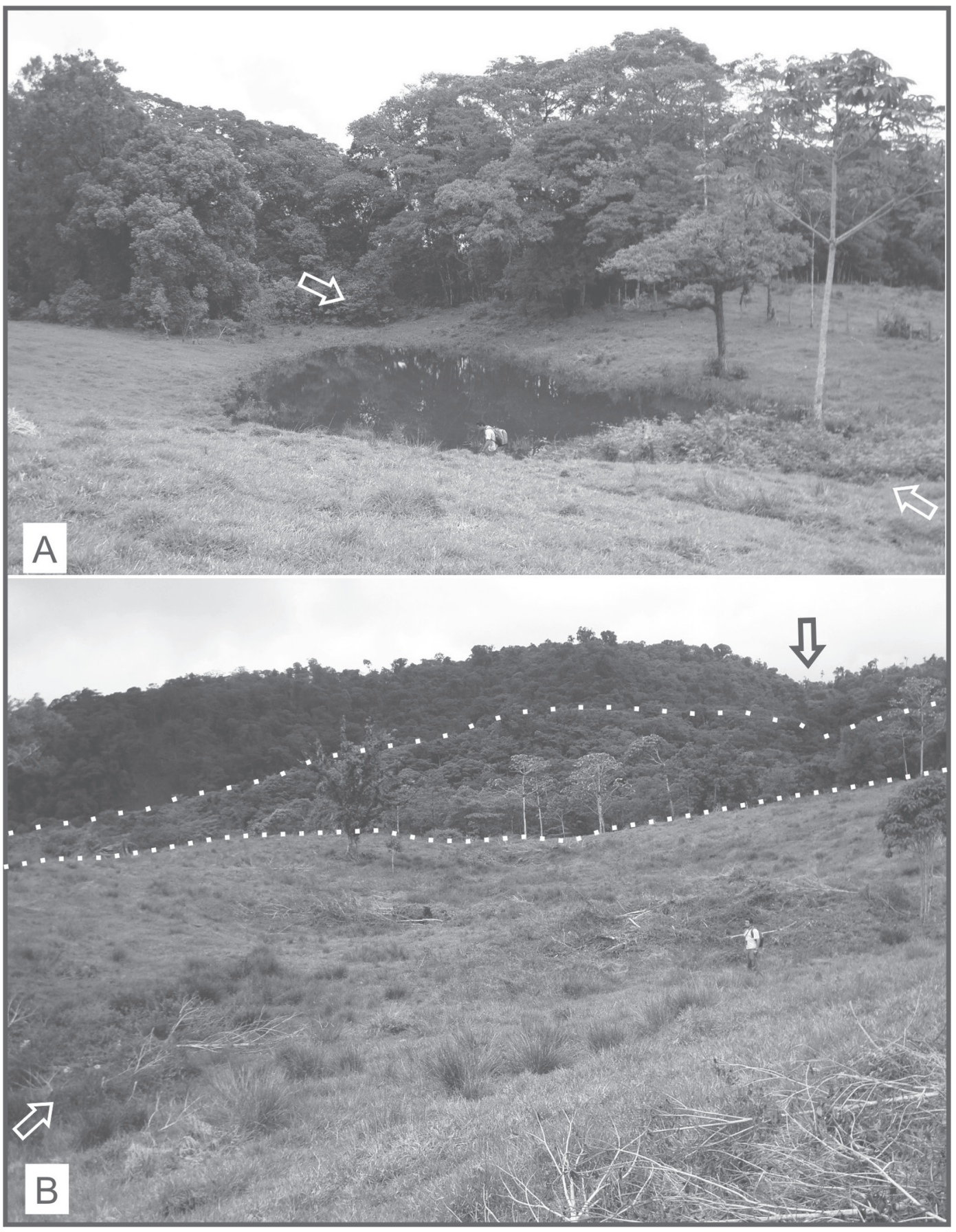

Fig. 8: A) Vista al noreste de una laguna de falla asociada con un contraescarpe observada en la finca Montaña Azul (sitio 6 en Fig. 2). Las flechas muestran el trazo sugerido de la falla Ángel con rumbo N-S. B) Vista al SSE de la falla Ángel evidenciada por contraescarpes facetados al oeste que interrumpen la pendiente regional al este (marcada por líneas a puntos blancas). Las flechas muestran el rumbo al S de la falla Ángel (sitio 6 en Fig. 2). El Geól. Carlos Vargas ubicado sobre el bloque oeste de la falla define la escala. 
alcanzar estas fallas se vuelven paralelos a las fallas drenando al NNW (sector norte de fallas) o al SSE (sector sur de fallas). Se interpretan como grábenes volcánicos aunque localmente podrían tener una componente dextral.

\section{Falla Sabanilla}

En este trabajo se define por primera vez la falla Sabanilla (Fig. 2). La traza se extiende por más de $25 \mathrm{~km}$ de largo con un rumbo NW, siendo más prominente en sus sectores central y norte. $\mathrm{Al}$ este, la falla tiene un trazo incierto y pierde continuidad al acercarse a la falla Alajuela. Hacia el norte la falla tiene un relevo izquierdo con la falla Viejo - Aguas Zarcas. El trazo de esta falla coincide en algunos sectores parcialmente con algunos lineamientos del sistema Sabanilla-San Isidro referido por Woodward-Clyde (1993).

\section{Geomorfología}

El trazo identificado para esta falla se inicia al noroeste cerca de la población de Bajos del Toro (Fig. 2) donde muestra sillas de falla y un escarpe facetado al E. Continuando al sureste, la falla corta diversas estribaciones en las faldas oeste y suroeste del volcán Poás. En este sector la falla se evidencia por divisorias, quebradas y ríos desviados en forma derecha, aunque hay también drenajes adaptados, sillas de falla, escarpes, valles lineales y descansos en la topografía. Sobre la falda sur y sureste del volcán Poás, se observan quebradas y ríos descabezados, bermas de falla, contraescarpes, valles lineales, ríos y quebradas desviados o adaptados, entre otros (sitios 12 y 13 en Fig. 2; Fig. 9).

\section{Geología estructural}

En el extremo noroeste es notoria la presencia de una cuenca anómala rellena de depósitos aluviales y lahares asociados con varios afluentes del curso superior del río Toro (Fig. 2). Se puede

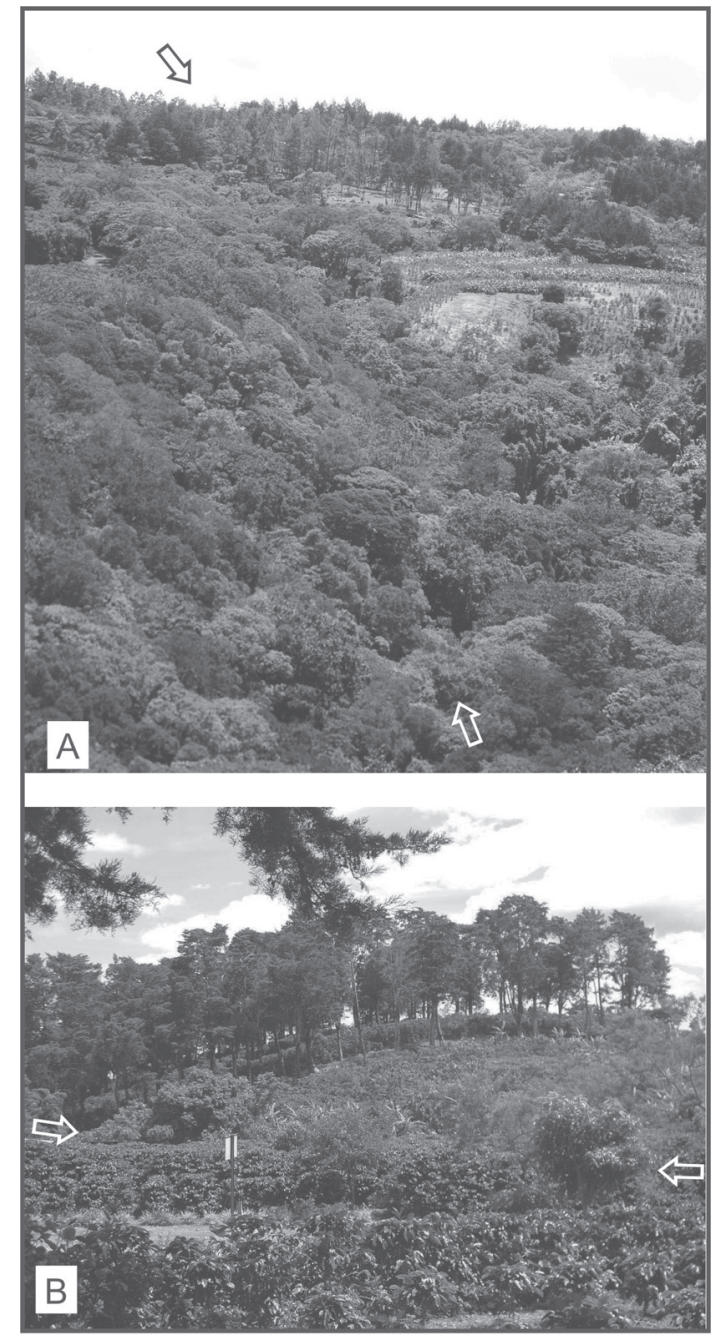

Fig. 9: A) Vista al noroeste desde sitio 12 (Fig. 2) de valle lineal y contraescarpe a lo largo de la falla Sabanilla (trazo marcado por flechas). Al fondo leve quiebre en pendiente. B) Vista al sur desde sitio 13 (Fig. 2) mostrando contraescarpe facetado al norte asociado a falla Sabanilla (trazo marcado por flechas).

interpretar que donde la falla corta a través de esta cuenca, la desplaza dextralmente. Falta realizar una investigación de campo detallada que permita encontrar evidencias estructurales de esta falla.

\section{Falla Carbonera}

La falla Carbonera fue originalmente descrita por Alvarado et al. (1988), quienes la ubicaron en 


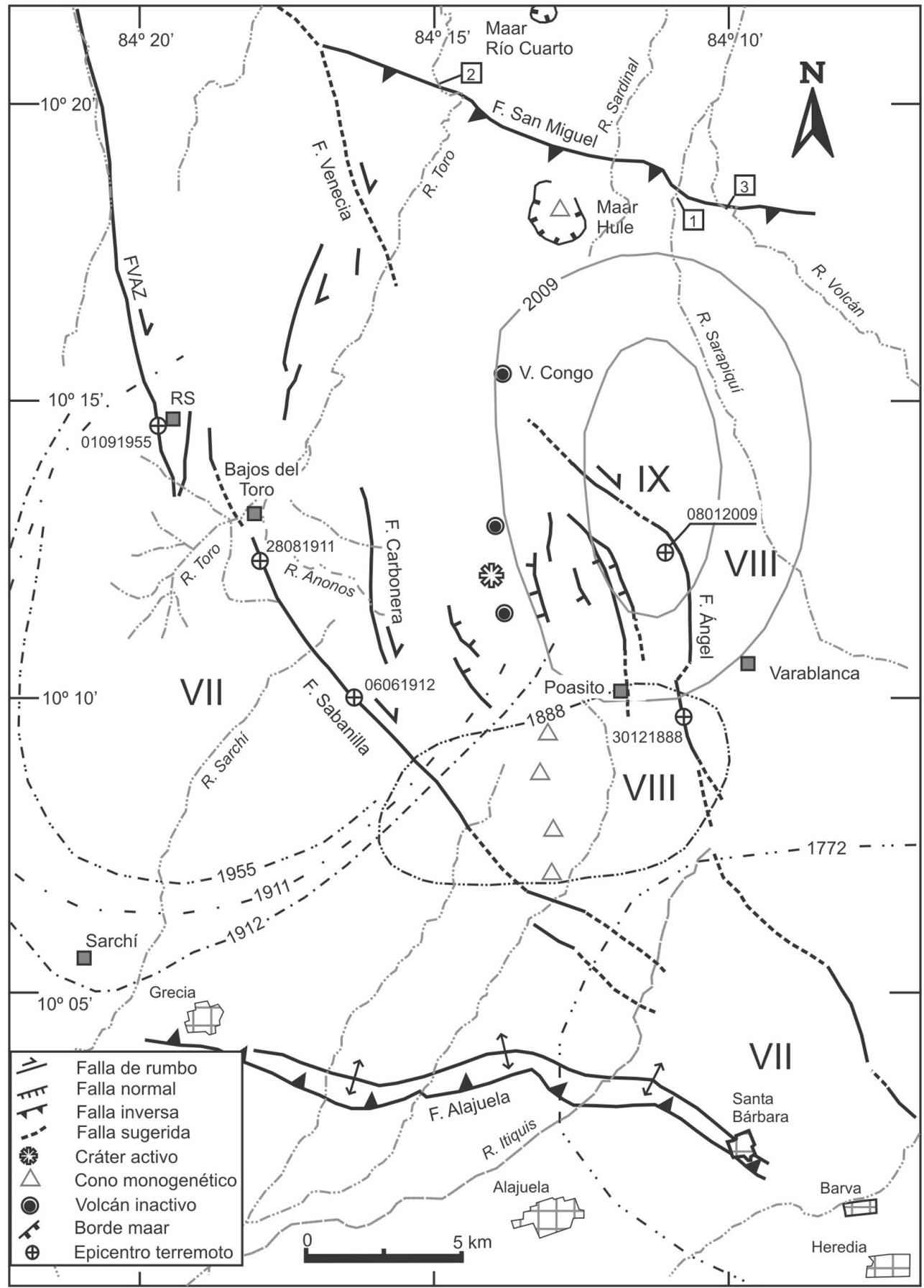

Fig. 10: Relación entre los terremotos históricos y las fallas del macizo del volcán Poás. Se muestran las isosistas de máxima intensidad de los diversos terremotos con diferentes simbologías y con el año del sismo correspondiente obtenidas de Alvarado et al, (1988) excepto para el terremoto del 2009 que provienen de Rojas et al. (2009). FVAZ es la falla Viejo-Aguas Zarcas. 
el sector occidental del volcán Poás, con una longitud mínima de 6,5 km y un rumbo NNW (Fig. $2)$. La caracterizaron por sus prominentes escarpes que en parte definen una garganta de falla y divisorias de aguas ligeramente desplazadas en sentido dextral en diferentes sectores de su traza.

El principal desvío dextral que se sugiere son divisorias de aguas desplazadas y el del río Anonos (Fig. 10), aunque este último puede haber sido alargado por erosión a lo largo de la falla, o por captura de drenajes, dado que tiene un largo de $1,2 \mathrm{~km}$ de longitud, que es muy grande en relación con la longitud de la falla.

Barquero et al. (2007) presentan un perfil geomagnético (realizado por C. Leandro en el ICE) de rumbo E-W transversal a la falla. En él se observa que del lado oeste de la falla hay anomalías positivas entre 0 y 250 gammas. Al pasar la falla hay un mínimo magnético menor a 0 gammas y luego del lado este, la anomalía se incrementa hasta cerca de 750 gammas.

Aunque no existe evidencia geológica de esta falla observada en el campo, se considera que las evidencias morfotectónica y geofísica son bastante concluyentes acerca de su existencia.

\section{Falla Viejo - Aguas Zarcas}

Fue descrita por primera vez por Alvarado et al. (1988), quienes la consideran una falla en tijera de una longitud mínima de $25 \mathrm{~km}$. Una estructura de características similares se muestra en el mapa geológico de Costa Rica (DGMP, 1982). Es una falla poco estudiada y se caracteriza por su valle lineal a lo largo del río Aguas Zarcas (Fig. 7).

Barquero et al. (2007) muestran un perfil magnético (también realizado por C. Leandro en el ICE), que posee una dirección transversal a la falla. Se observa que del lado oeste de la falla hay una anomalía magnética de unas 350 gammas; al pasar la falla, la anomalía disminuye a un mínimo cercano a 0 gammas, y del lado este de la falla, la anomalía se incrementa hasta cerca de 750 gammas. Lo anterior sugiere un contraste entre las susceptibilidades magnéticas de las rocas presentes en ambos lados de la falla.

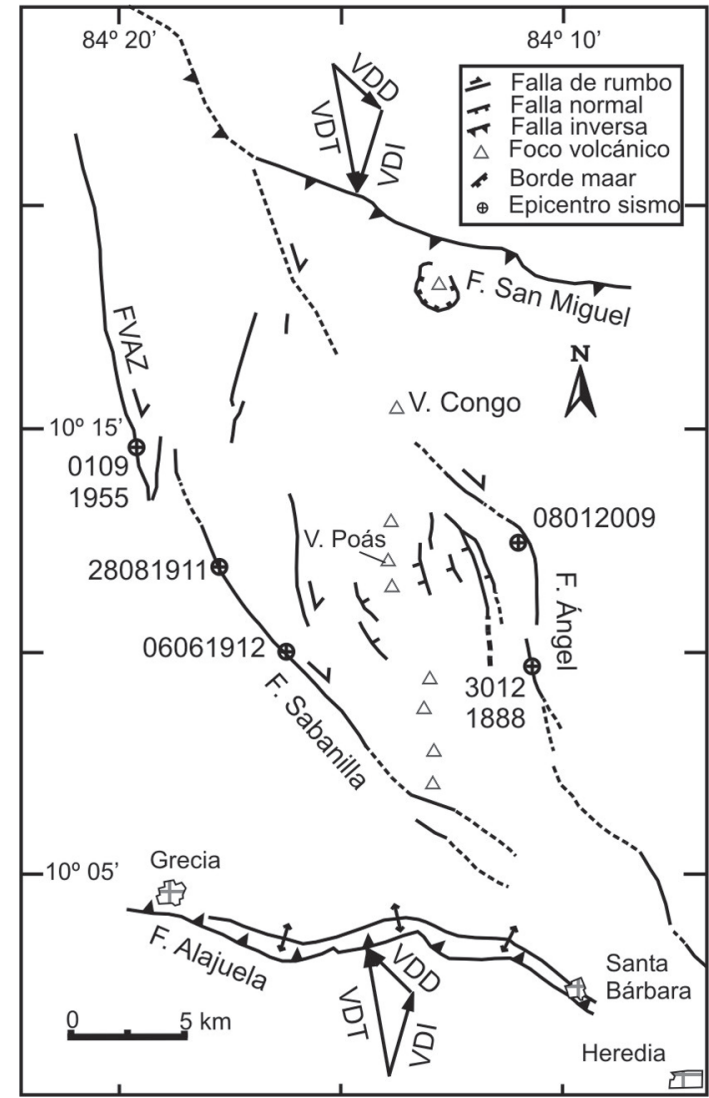

Fig. 11: Modelo de división del deslizamiento tectónico regional entre las fallas de desplazamiento dextral y las de fallamiento inverso dentro del macizo Poás. FVAZ es la falla Viejo-Aguas Zarcas. VDT, VDD y VDI son respectivamente el vector de deslizamiento tectónico regional, la componente de desplazamiento dextral y la componente de desplazamiento que mueve las fallas inversas.

\section{Falla San Miguel}

Sobre el sector norte del macizo volcánico del Poás, la falla más relevante es la falla San Miguel, que tiene un rumbo general $\mathrm{N} 70^{\circ} \mathrm{W}$ y una longitud cercana a los $15 \mathrm{~km}$ (Fig. 7). Esta falla se caracteriza por su escarpe bastante rectilíneo, relativamente poco disectado, juvenil y con facetamiento rectangular en algunos sectores a parcialmente erosionado y bastante disectado en otros sectores (Soto, 1999; Arroyo \& Alvarado, 2002). Aguas arriba del escarpe, los ríos tienen 
cañones profundos, indicando que son antecedentes a la estructura tectónica. El escarpe tiene una altura máxima de $160 \mathrm{~m}$ en su parte central, disminuyendo hacia el este y el oeste. Borgia et al. (1990) han interpretado que este escarpe representa el flanco delantero de un pliegue asociado con una falla de propagación inversa. Esta falla y la de Alajuela se ubicarían a distancias similares del eje del volcán Poás.

Soto $(1990 ; 1999)$ propone que la falla San Miguel presenta diferentes características morfológicas y estructurales en diversos sectores y encuentra que los depósitos epiclásticos y de piedemonte recientes (no hay edades, pero los asumen del Pleistoceno tardío - Holoceno) se encuentran ligeramente deformados al norte del maar de Hule.

Entre las observaciones que pueden dar evidencia de que la falla San Miguel es potencialmente activa se tienen: 1- La presencia de fuentes termales y salidas de gases alineadas paralelas al escarpe (aguas bicarbonatadas y con emanaciones de $\mathrm{CO}_{2}$ y $\mathrm{CH}_{4}$; Zimmer et al., 2004) ubicadas en los ríos Sarapiquí, Sardinal y Toro, coincidentes con el trazo de la falla (Fig.10). 2- Una doble flexura morfológica a lo largo del escarpe, que comban depósitos de edad relativamente joven como son los lahares, epiclastos y sedimentos en el labio superior del escarpe y en su pie (Soto, 1999). Esto sugiere una falla inversa doble, con planos buzantes al SSW, con plegamiento superficial y reciente, acordes con la propuesta de Borgia et al. (1990). 3- Un acentuado cambio en el patrón del río Sarapiquí (sitio 1 en Fig. 10), que discurre encañonado por varios kilómetros, casi rectilíneo, y hace una fuerte curva encañonada precisamente en el limbo de la flexura mencionada en el punto anterior. Esto sugiere un levantamiento rápido, que cambió la estrategia erosiva del río, y que una vez vencido el obstáculo, se torna ligeramente trenzado (tal como se observa en las fotos aéreas) con terrazas aluviales y cauces abandonados o casuales. 4- Un cambio anómalo en el patrón del río también se observa en el río Toro donde se han reco- nocido cauces abandonados y un río descabezado (Arroyo \& Alvarado, 2002; sitio 2 en Fig. 10) y en el río Volcán (sitio 3 en Fig. 10). 5- Una serie de paleodeslizamientos a lo largo del escarpe.

\section{Diversas fallas o lineamientos sugeridos en la literatura}

Aparte de las fallas anteriormente descritas dentro del macizo del volcán Poás, otras fallas o lineamientos han sido sugeridos en la literatura. Entre estas tenemos el sistema de lineamientos de Sabanilla-San Isidro (Woodward-Clyde, 1993), algunos de los cuales, como mencionamos anteriormente, concuerdan parcialmente con la falla Sabanilla descrita en este trabajo. Sobre la falda noreste del volcán Poás, Soto (1999) describe unas estructuras perpendiculares al río Sarapiquí, que afectarían la secuencia volcánica antigua del Paleo-Poás y subyacente $(>200 \mathrm{ka})$. Estas fallas podrían estar inactivas y su rol tectónico actual es desconocido, por lo que merecen un mayor estudio.

Gazel \& Ruiz (2005) proponen una falla ubicada en las laderas y el cauce del río Poás, de un rumbo noreste-suroeste y un movimiento relativo sinestral inferido con base en evidencias fotogeológicas. Esta supuesta falla se ubicaría dentro de la estructura limitada por las fallas Sabanilla y Ángel. Sin embargo, no encontramos evidencia morfotectónica de ella.

Arroyo \& Alvarado (2002) muestran una serie de lineamientos estructurales de rumbo noroeste del lado norte del volcán Poás que merecen mayor investigación. Estos serían compatibles con el sistema neotectónico propuesto en este trabajo. Como se mencionó, uno de estos lineamientos que ha sido denominado falla Venecia (Barquero et al., 2007), puede ser la continuación noroeste de la falla Ángel.

Una falla sugerida que ha sido motivo de controversia en la literatura, tendría una traza de rumbo 
noreste bastante paralela con el río Toro (Fig. 10). Aunque aparece en varios mapas geológicos (por ejemplo, DGMP, 1982), sin embargo, diversas investigaciones realizadas en esta zona no han mostrado evidencia de ella (Arroyo \& Alvarado, 2002; Barquero et al., 2007). Un criterio similar tenemos en este estudio.

\section{RELACIÓN ENTRE LAS FALLAS Y LA SISMICIDAD RECIENTE}

La figura 7 muestra la relación entre la sismicidad reciente y las fallas del macizo Poás y zonas adyacentes. Se muestra una sismicidad dispersa entre el norte de la falla Alajuela y el sur de la falla Sabanilla, que podría relacionarse con la falla inversa de Alajuela. Una importante cantidad de temblores se localiza entre las fallas Sabanilla y Ángel, donde se incluyen las fallas Carbonera y las cuspidales del Poás. Una parte significativa de esa sismicidad parece seguir el trazo de los sectores central y norte de la falla Sabanilla. Fernández \& Pacheco (1998) muestran una distribución de temblores similar. Por otro lado, una serie de temblores parece seguir el sector de rumbo NNW a N de la falla Ángel. Algunos sismos se localizan a lo largo del sector sur de la falla Viejo - Aguas Zarcas. Finalmente, se observa una sismicidad al sur de la falla San Miguel, con la cual se puede asociar. Las anteriores relaciones entre la sismicidad reciente y las fallas del macizo del Poás sugieren que las diversas fallas identificadas son fallas activas.

\section{RELACIÓN ENTRE LAS FALLAS Y LA SISMICIDAD HISTÓRICA}

Dentro del macizo del volcán Poás han ocurrido seis terremotos históricos que se pueden asociar con el sistema de fallas descrito anteriormente. Estos han sido los sismos del 15 de febrero de 1772, 30 de diciembre de 1888, 28 de agosto de
1911, 6 de junio de 1912, $1^{\circ}$ de setiembre de 1955 y el reciente terremoto del 8 de enero del 2009 (Alvarado et al., 1988; Peraldo \& Montero, 1994; Cuadro 1). No se incluye en esta lista el terremoto del 28 de marzo de 1851, porque los daños que causó no están claramente asociados con lugares o poblados ubicados dentro del macizo del Poás. Así, el principal reporte sobre este sismo aparecido en La Gaceta (transcrito en González, 1910) señala que originó daños en San José, donde se reportaron 145 casas afectadas, de las cuales $18 \mathrm{se}$ mandaron demoler y además echó abajo la torre de la iglesia Catedral. Indica que el temblor parece que fue más fuerte en Heredia y en Alajuela, donde se sugiere ocurrieron los mayores daños, aunque no existe un reporte detallado que así lo demuestre, y agrega que el sismo se sintió hasta en Guanacaste.

A continuación describimos brevemente los sismos mencionados y proponemos la fuente de origen.

\section{El terremoto del 15 de febrero de 1772}

Este sismo originó deslizamientos en la falda sur del volcán Barva y causó daños importantes en diversas construcciones de Barva y Heredia (Peraldo \& Montero, 1994; Fig. 10). Von Frantzius (1861) había descrito unos flujos de detritos en el río Itiquís a raíz de este terremoto. Peraldo \& Montero (1994) asocian el terremoto con la falla de Alajuela, sitúan su epicentro en la cercanía del cerro Chompipe y estiman una intensidad máxima Mercalli Modificada entre VII y VIII grados.

Con base en el nuevo detalle cartográfico de fallas y el trazo sugerido en este trabajo para la isosista de intensidad VII (Fig. 10), se interpreta que este evento se pudo originar en el segmento al este de la unión entre las fallas Sabanilla y Ángel, el segmento sur de la falla Ángel, el sector este de la falla Sabanilla o en el sector este de la falla Alajuela (Fig. 10). No se escoge un epicentro porque la ubicación de este sismo es muy ambigua. 
Cuadro 1

Parámetros focales de los terremotos en el macizo Poás

\begin{tabular}{|c|c|c|c|c|}
\hline \multirow{2}{*}{ Año, mes, día } & \multirow{2}{*}{ Magnitud } & \multicolumn{2}{|c|}{ Nueva ubicación interpretada } & \multirow{2}{*}{$\begin{array}{l}\text { Falla de origen } \\
\text { propuesta }\end{array}$} \\
\hline & & Latitud & Longitud & \\
\hline $1772-02-15$ & $\mathrm{M} \sim 5,5-6,0$ & ------- & ------- & $\begin{array}{c}\text { Ángel, Sabanilla o } \\
\text { Alajuela? }\end{array}$ \\
\hline $1888-12-30$ & $M_{L} 5,7^{1}$ & $10^{\circ} 09,5^{\prime}$ & $84^{\circ} 11,0^{\prime}$ & Ángel \\
\hline $1911-08-28$ & $M_{s} 5,8^{2}$ & $10^{\circ} 12,0^{\prime}$ & $84^{\circ} 18,0^{\prime}$ & Sabanilla \\
\hline 1912-06-06 & $\mathrm{M}_{\mathrm{s}} 5,1^{2}$ & $10^{\circ} 10,0^{\prime}$ & $84^{\circ} 17,0^{\prime}$ & Sabanilla \\
\hline 1955-09-01 & $M_{s} 5,5^{2}$ & $10^{\circ} 14,5^{\prime}$ & $84^{\circ} 19,5^{\prime}$ & $\begin{array}{l}\text { Viejo-Aguas } \\
\text { Zarcas }\end{array}$ \\
\hline 2009-01-08 & $M_{w} 6,1^{3}$ & $10^{\circ} 11,5^{\prime}$ & $84^{\circ} 11,0^{\prime}$ & Ángel \\
\hline
\end{tabular}

${ }^{1}$ Magnitud local obtenida por Alvarado et al. (1988), ${ }^{2}$ Magnitud de onda superficial obtenida por Ambraseys \& Adams (2001), ${ }^{3}$ Magnitud de tensor momento de Harvard.

\section{El Terremoto de Fraijanes, del $\mathbf{3 0}$ de diciembre de $1888\left(M_{L} 5,7\right)$}

Este sismo originó grandes deslizamientos en la falda sureste del volcán Poás y provocó importante destrucción en diversas construcciones de las ciudades de Alajuela y Heredia y en menor medida en la ciudad de San José (González, 1910; Alvarado et al., 1988). Alvarado et al. (1988) estimaron una intensidad máxima de VIII en la zona mesosísmica. Este temblor fue atribuido a la actividad de la falla de Alajuela o a la falla Ángel (Alvarado et al., 1988; Peraldo \& Montero, 1994). En el informe elaborado por Henri Pittier en enero de 1889, el cual aparece transcrito en González (1910), se describe con gran detalle los daños a las construcciones y los efectos sobre el terreno, los cuales fueron de mayor importancia hacia la zona alta entre los volcanes Poás y Barva, incluyendo la zona de divisoria de aguas continental entre Varablanca y Poasito (Fig. 10). Morales et al. (1992) consideraron que una depresión que se ubica en la cuenca superior del río Poás, donde ocurre un cambio en la dirección del drenaje de WNW a $\mathrm{NE}$, como es el caso del río Desengaño, fue donde se ubicó el área epicentral de ese sismo (Fig. 2). Lo anterior en concordancia con la zona más afectada por el terremoto según los informes de Pittier y Michaud (en González, 1910). Efectivamente, las observaciones de daños y deslizamientos más importantes se localizaron a lo largo de la traza de la falla Ángel o cerca de esta. Estos deslizamientos todavía pueden ser distinguibles en las fotos aéreas y sugieren fuertemente que el terremoto de 1888 se originó en la falla Ángel. Asimismo, el trazo de la falla Ángel fue donde se determinó la zona mesosísmica de intensidad VIII (Alvarado et al., 1988; Fig. 10). Con base en lo anterior, proponemos el epicentro de este sismo en la falla Ángel (ubicación en cuadro 1 y Figura 10). Una ruptura en la falla Alajuela es menos probable porque los deslizamientos se presentaron en una zona estrecha y alargada en la dirección de la falla Ángel. Si hubiera ocurrido una ruptura en el segmento oeste de la falla de Alajuela, se hubiera esperado que sucedieran deslizamientos en una región más extensa, incluyendo desde el norte de Alajuela hacia Grecia, lo cual no parece haber sido el caso.

\section{El terremoto del 28 de agosto de $1911\left(M_{s} 5,8\right)$}

Este sismo ha sido atribuido a la falla Viejo - Aguas Zarcas (más probable) o con la falla Carbonera (Alvarado et al., 1988). Los datos macrosísmicos indican que la zona más afectada se ubica en las cabeceras del río Toro, donde ocurrieron una gran cantidad de deslizamientos, mientras que los daños fueron menores en los poblados localizados sobre la falda sur del macizo del 
Poás (Alfaro et al., 1912; Fig. 10). Los daños en el poblado de Bajos del Toro fueron leves porque la mayoría de las construcciones eran de madera. Alvarado et al. (1988) estimaron una intensidad máxima de VII. Asociamos este sismo con el extremo norte de la falla Sabanilla porque está en concordancia con la zona mesosísmica y porque como veremos adelante, junto con los sismos de 1912 y 1955 originaron una secuencia de rupturas entre los segmentos de fallas Sabanilla (sector central-norte) y el sector sur de la falla Viejo - Aguas Zarcas (Fig. 10).

\section{El terremoto del 6 de junio de $1912\left(M_{s} 5,1\right)$}

Al igual que el evento anterior, este sismo fue asociado con la falla Viejo - Aguas Zarcas (más probable) o con la falla Carbonera (Alvarado et al., 1988). De acuerdo con los anteriores autores la zona más afectada por deslizamientos se ubicó en las nacientes de los ríos Anonos y Sarchí (Fig. 10). Además, hubo daños en casas en diversos poblados ubicados sobre la falda suroeste del volcán Poás incluyendo la ciudad de Grecia. Alvarado et al. (1988) estimaron una intensidad máxima de VII. Se considera que este terremoto se originó en el sector central-norte de la falla Sabanilla, porque la zona más afectada por deslizamientos cubre este sector de la falla y el área mesosísmica sugerida por los daños en poblados está más acorde con esta falla que con las fallas Viejo - Aguas Zarcas o Carbonera (epicentro en Fig. 10).

\section{El terremoto del $1^{\circ}$ de setiembre de $1955\left(M_{s} 5,5\right)$}

Igual que los dos sismos anteriores, este terremoto fue asociado con la falla Viejo - Aguas Zarcas (más probable) o con la falla Carbonera (Alvarado et al., 1988). Los anteriores autores indican que este evento causó la destrucción de casas en Río Segundo (RS en Fig. 10) y la formación de largas grietas y deslizamientos. Además, se reportaron serios daños en Grecia y otros poblados cercanos. Estimaron una intensidad máxima de VII que pudo llegar a VIII. Este sismo lo relacionamos con el extremo sur de la falla Viejo
- Aguas Zarcas, considerando los daños en el poblado de Río Segundo (epicentro en Fig. 10).

\section{El Terremoto de Cinchona, del 8 de enero del $2009\left(M_{w} 6,1 ; M_{s} 6,1\right)$}

Este reciente sismo provocó considerables daños en construcciones y deslizamientos sobre la falda este y noreste del volcán Poás, aunque también los hubo sobre las faldas sur y sureste (Méndez et al., 2009). La máxima intensidad MM fue IX grados. Este sismo se relacionó con el sector donde la falla Ángel tiene un rumbo $\mathrm{N} 50^{\circ} \mathrm{W}$ (Rojas et al., 2009; Fig. 8).

\section{DISCUSIÓN}

\section{El sistema de falla Ángel - Sabanilla - Aguas Zarcas}

Las fallas Ángel, Sabanilla, Carbonera y Viejo - Aguas Zarcas y las estructuras cuspidales del volcán Poás conforman un sistema de fallas relacionadas que interactúan entre sí (Fig. 7). Este sistema de fallas tiene dos brazos principales, el ubicado del lado este y norte del macizo del Poás constituido por la falla Ángel, y el del lado oeste y sur constituido por las fallas Sabanilla, Carbonera y Viejo - Aguas Zarcas. Es posible que brazos se unan al sureste del macizo del volcán Poás y continúen como una sola falla sobre la falda sur del volcán Barva. Igualmente, es de esperar que la falla Ángel continúe hacia el noroeste hasta alcanzar la falla San Miguel, tal como lo sugiere un lineamiento identificado en Arroyo \& Alvarado (2002) y denominado falla Venecia por Barquero et al. (2007). Ambos ramales tienen un desplazamiento predominantemente dextral, aunque estas fallas también tienen una componente normal en ciertos sectores, como lo muestra la morfología de la falla Ángel donde tiene un rumbo cercano al norte-sur, al este del volcán Poás. La falla Ángel también tiene una pequeña componente normal en su sector de rumbo $\mathrm{N} 50^{\circ} \mathrm{W}$, al noreste del volcán Poás, tal como se determinó con la solución del centroide del tensor de momento de Harvard para el terremoto de Cinchona del 8 de enero del 2009. 
El plano nodal de movimiento predominantemente dextral tiene una pequeña componente normal (deslizamiento de $-174^{\circ}$ a lo largo de una falla de rumbo $\mathrm{N} 52^{\circ} \mathrm{W}$ e inclinación de $79^{\circ}$ al SW, Fig. 7). Entre las dos ramas de falla se presenta una estructura transtensional, dentro de la cual se presentan las fallas cuspidales del volcán Poás, que son predominantemente normales. Además, como veremos a continuación se presentan diversas estructuras volcánicas como son el volcán Poás y los conos piroclásticos de Sabana Redonda.

\section{Fallas y estructuras volcánicas regionales}

Los conos piroclásticos de Sabana Redonda forman parte de un alineamiento de rumbo aproximado N-S en el sector sur del macizo del Poás, que se prolonga hasta el maar de Río Cuarto al norte del macizo (Alvarado, 1989; Soto \& Alvarado, 1989; Figs. 2, 7). Gazel \& Ruiz (2005) afirman que los conos de Sabana Redonda se localizan a lo largo de una depresión norte-sur limitada al este y oeste por unos escarpes lineales de pendientes fuertes $\left(25^{\circ}-45^{\circ}\right)$ de hasta $70 \mathrm{~m}$ de altura (FVP en Fig. 2). Más al norte de estas estructuras, se localizan el cráter Botos, el cráter actual del volcán Poás y el cono Von Frantzius (Fig. 2). De acuerdo con nuestro modelo tectónico, las anteriores estructuras volcánicas y los conos piroclásticos se ubicarían cerca de la zona media entre las fallas Ángel y Sabanilla. Dentro de la estructura tensional definida entre ambas fallas, la dirección de extensión tiene un rumbo E-W, por lo que el origen de estas estructuras estaría de acuerdo con los esfuerzos tectónicos imperantes.

Con respecto a las estructuras cuspidales del volcán Poás, Prosser \& Carr (1987) las han interpretado como los bordes de calderas cuspidales. Brown et al. (1987), basados en mediciones gravimétricas, encuentran materiales de baja densidad que parecen rellenar depresiones topográficas a profundidades de varios cientos de metros. Ellos asumieron lo mismo que los otros dos autores, por lo que desarrollaron un modelo a priori en que las estructuras son calderas. Soto (1999) considera que las supuestas calderas estarían cubiertas por los depósitos de Von Frantzius,
Botos y del cráter principal del volcán Poás, pero observa que el problema es que los depósitos de las erupciones plinianas o ignimbríticas cuya erupción originaría la caldera, no aparecen. Indica que la "lapilli tuff" que proponen Prosser \& Carr (1987), podría ser depósitos de pómez del Barva. Por lo anterior, Soto (1999) propone que las fallas de la cúspide del Poás, corresponden con una serie de grábenes curvilíneos (al igual que Alvarado, 1989), asociados con una dispersión lateral del Poás, que al oriente y occidente estaría obstaculizada por la oposición de las rocas del basamento de los macizos del Barva y Platanar. El anterior modelo es totalmente compatible con el nuestro, porque estas estructuras se ubican dentro de una zona transtensiva donde el eje de extensión está orientado al E-W. Igualmente, si se considera que la extensión está relacionada con esfuerzos regionales, los macizos Barva y Platanar no le hacen oposición, porque esta región está también en extensión E-W.

Es de observar que el volcán Congo, el conjunto volcánico Bosque Alegre, incluyendo sus conitos piroclásticos internos, y la laguna Hule y el maar de Río Cuarto (Fig. 7) se localizan fuera de la estructura transtensiva, pero están de acuerdo con la dirección de extensión E-W y con el esfuerzo compresivo horizontal máximo de rumbo $\mathrm{N}-\mathrm{S}$, ambos asociados con la tectónica regional.

\section{Rupturas históricas y amenaza sísmica}

Las nuevas localizaciones propuestas para los sismos históricos destructivos nos permiten proponer un modelo de rupturas sísmicas en el sistema de falla Ángel - Sabanilla - Aguas Zarcas. Este nos muestra que la falla Ángel ha originado al menos dos rupturas históricas, las cuales corresponden con los sismos de 1888 y 2009 y se puede agregar el sismo de 1772, aunque hay más ambigüedad con este último. Si el terremoto de 1772 ocurrió en la parte sur de la falla Ángel, se puede observar una secuencia de rupturas en esta falla que se ha propagado de sur a norte, donde entre los primeros dos sismos transcurrieron 116 años y entre los dos últimos 121 años. Este modelo de rupturas podría sugerir que la falla Ángel 
ya completó un ciclo de rupturas, aunque si esta falla se extiende más al noroeste como sugerimos, faltaría este sector de romperse. Un periodo de retorno sugerido en esta falla para sismos $\mathrm{M} \sim 5,5$ 6,0 es ligeramente superior a un siglo.

Con respecto a las fallas Sabanilla y Viejo - Aguas Zarcas, se propone una secuencia de rupturas históricas iniciada con el terremoto de 1911, el cual habría tenido epicentro en el sector norte de la falla Sabanilla. Esta falla rompió nuevamente en 1912 su sector central - norte y luego en 1955 ocurrió una nueva ruptura, en el sector sur de la falla Viejo - Aguas Zarcas y al norte del evento de 1911.

En nuestro modelo de sismicidad histórica, no encontramos evidencia de rupturas históricas en las fallas Alajuela (quizás 1772?) ni San Miguel. Tampoco se han determinado rupturas en los sectores norte de la falla Viejo - Aguas Zarcas y el sector central-sureste de la falla Sabanilla y sureste de la falla Ángel (tal vez 1772?). Un sismo en los últimos sectores de las fallas Sabanilla o Ángel sería potencialmente desastroso para las poblaciones ubicadas sobre la falda sur del volcán Poás y el oeste del valle Central o una reactivaciòn de la falla Viejo-Aguas Zarcas para la población de Aguas Zarcas. El terremoto del 28 de marzo de 1851 es un sismo que merece mayor investigación, dado que podría relacionarse con el sector central-sureste de la falla Sabanilla, con la falla de Alajuela o con alguna otra fuente sísmica.

Se considera que las diversas fallas, por su longitud, podrán generar sismos someros de $\mathrm{M}<6,5$, con aceleraciones pico máximas $>0,5 \mathrm{~g}$, que afectarían severamente áreas de $\sim 10 \mathrm{~km}$ de radio alrededor de sus epicentros, generando deslizamientos de importancia, lahares y daños a infraestructura vial y civil.

\section{Modelo tectónico y origen de los esfuerzos}

Se han presentado dos modelos tectónicos para explicar los esfuerzos que han originado varias de las estructuras del macizo del Poás. Estos son el de Borgia et al. (1990), quienes consideraron que las fallas de Alajuela y de San Miguel son causadas por el deslizamiento gravitacional del edificio volcánico del Poás, ayudado por esfuerzos magmáticos distensivos generados en su eje volcánico. Por su parte, Montero (1994b) consideró que son los esfuerzos regionales los que controlan la orientación de estas estructuras. $\mathrm{La}$ argumentación a favor de la segunda propuesta fue que la dirección de estas estructuras es correspondiente con las direcciones de esfuerzos actuales en el centro de Costa Rica (cf. Montero \& Morales, 1990; Montero, 1994b; López, 1999). Estas direcciones de esfuerzos son muy similares a las que afectaron las rocas que conforman la cuenca Candelaria (Arias \& Denyer, 1991) y el Grupo Aguacate (Arias \& Denyer, 1994), lo que implicaría que el sistema de esfuerzos ha sido consistente desde el Mioceno terminal (basado en que la Formación Grifo Alto, de $<5,5 \mathrm{Ma}$, no está basculada) hasta el presente.

Los nuevos resultados aportados por este estudio nos permiten concluir que la presencia del sistema de falla Ángel - Sabanilla - Aguas Zarcas, localizado entre las fallas Alajuela y San Miguel, es totalmente incompatible con el modelo de Borgia et al. (1990), pero es más compatible con el modelo que relaciona estas estructuras con la tectónica regional. Asimismo, se observa claramente que las fallas Alajuela y San Miguel solo se extienden hacia el este y el oeste dentro de la zona donde se localiza la zona transtensiva del sistema de falla Ángel-Sabanilla-Aguas Zarcas. Una vez que se alcanzan las fallas Aguas Zarcas al oeste y la posible zona de unión entre las fallas Ángel-Sabanilla al sureste, las fallas Alajuela y San Miguel pierden desplazamiento hasta desaparecer.

Un resultado relevante de este estudio es la relación entre las fallas de desplazamiento predominantemente dextral del sistema Ángel Sabanilla - Aguas Zarcas con las fallas inversas Alajuela y San Miguel. Se propone que existe una división del deslizamiento tectónico regional (slip partitioning) entre las fallas dextrales e inversas al norte y al sur del volcán Poás (Fig. 11). Se considera que el vector de deslizamiento regional, que se relaciona con el movimiento del bloque Nicoya al noroeste con respecto a la placa Caribe (Fig. 1), es aproximadamente paralelo al rumbo de la falla Viejo - Aguas Zarcas, es decir, tiene un 
rumbo $\mathrm{N} 10^{\circ} \mathrm{W}$. Al este de esta falla y dentro del macizo Poás, el deslizamiento tectónico se divide entre las fallas inversas y las dextrales Ángel y Sabanilla. El rumbo predominante de las fallas inversas es $\mathrm{N} 75^{\circ} \mathrm{W}$ y un movimiento inverso puro sería con un rumbo $\mathrm{N} 15^{\circ} \mathrm{E}-\mathrm{S} 15^{\circ} \mathrm{W}$. El rumbo de la fallas Ángel y Sabanilla varía entre $\mathrm{N} 15^{\circ} \mathrm{W}$ y $\mathrm{N} 75^{\circ} \mathrm{W}$. Un rumbo intermedio es $\mathrm{N} 45^{\circ} \mathrm{W}$, el cual es bastante cercano al del vector deslizamiento obtenido para el terremoto de Cinchona por Harvard, que fue de $-174^{\circ}$ a lo largo de una falla de rumbo $\mathrm{N} 52^{\circ} \mathrm{W}$ e inclinación de $79^{\circ}$ al SW (Fig. 7). Dado que se desconoce cómo se divide el deslizamiento tectónico entre las diversas fallas del macizo Poás, para ejemplificar cómo puede darse la división de deslizamiento entre las diversas fallas, se supone un vector de magnitud unitaria a lo largo de un rumbo $\mathrm{N} 10^{\circ} \mathrm{W}$ y este se divide en 0,5 de deslizamiento dextral a lo largo de un rumbo $\mathrm{N} 45^{\circ} \mathrm{W}$ y 0,65 de deslizamiento inverso a lo largo de un eje de rumbo $\mathrm{N} 15^{\circ} \mathrm{E}-\mathrm{S} 15^{\circ} \mathrm{W}$. De acuerdo con la sismicidad histórica, parece observarse que las fallas de rumbo dextral muestran deslizamiento sísmico. Esto podría indicar que una parte importante del deslizamiento tectónico en el sistema de falla inverso se está originando por movimiento asísmico a lo largo de un plano de decollement y por deformación plástica, es decir, vía plegamiento en su parte frontal.

\section{CONCLUSIONES}

Como resultado de la presente investigación se ha reconocido el sistema de falla predominantemente dextral Ángel - Sabanilla - Aguas Zarcas, que incluye las fallas Ángel, Carbonera, Viejo - Aguas Zarcas y Sabanilla, esta última definida por primera vez en este trabajo. Dentro de los nuevos hallazgos reportados está la extensión al sur del trazo de la falla Ángel y además se sugiere su extensión más al noroeste. Dentro del sistema de falla mencionado, se presenta una estructura transtensiva, dentro de la cual se ubican las fallas cuspidales del Poás de movimiento predominante normal, los conos piroclásticos de Sabana Redonda, y los focos volcánicos de Botos, Poás y Von Frantzius. La presencia de una zona transtensiva en el volcán Poás sería la segunda determinada dentro de la Cordillera Central. Montero (2003) había interpretado una estructura similar, que incluye el macizo volcánico del Irazú y el Turrialba y que denominó "la cuenca de tracción Turrialba - Irazú" (Fig. 1).

El sistema de falla Ángel - Sabanilla - Aguas Zarcas, junto con las fallas Alajuela y San Miguel, caracterizados por sus pliegues asociados con fallas de propagación inversa, definen el sistema tectónico del macizo del Poás. Este arreglo geométrico de fallas que interactúan entre sí, se explica por la división del deslizamiento (slip partitioning) entre las fallas inversas San Miguel y Alajuela y las predominantemente dextrales Ángel, Sabanilla, Carbonera y Viejo - Aguas Zarcas. Se considera que el vector de deslizamiento regional, relacionado con el movimiento relativo del bloque Nicoya al noroeste con respecto a la placa Caribe (Fig. 1), es aproximadamente paralelo a la falla Viejo - Aguas Zarcas, por lo que dentro del macizo del Poás, parte del deslizamiento ocurre a lo largo de las fallas inversas a lo largo de una dirección cercana al $\mathrm{N} 15^{\circ} \mathrm{E}-\mathrm{S} 15^{\circ} \mathrm{W}$ y de las fallas Ángel y Sabanilla a lo largo de una dirección aproximada $\mathrm{N} 45^{\circ} \mathrm{W}$. Finalmente, se ha reinterpretado la fuente de origen de los terremotos históricos de 1772, 1888, 1911, 1912 y 1955 y se propone un modelo de rupturas que incluye el reciente terremoto de Cinchona del 8 de enero del 2009 , donde se sugieren sectores de falla sin rupturas recientes, con los cuales se asociaría la mayor amenaza sísmica dentro del macizo del Poás, aunado a los lahares y deslizamientos disparados por los terremotos.

\section{AGRADECIMIENTOS}

A los compañeros Héctor Flores y Carlos Vargas por su colaboración en el trabajo de campo realizado en la investigación de la falla Ángel. Maikol Rojas colaboró en el trabajo de campo de la falla Sabanilla. La participación de Walter Montero y de Wilfredo Rojas se realizó dentro de las actividades del proyecto de investigación 830-A8-133 de la Universidad de Costa Rica, y la de Gerardo J. Soto dentro de 
los proyectos $830-A 7-511$ y $113-A 9-509$ de la Universidad de Costa Rica y CONARE, respectivamente. Se agradece al ICE por su aporte en el conocimiento tectónico y de amenaza sísmica para uso directo en sus proyectos eléctricos y de telecomunicaciones, algunos de cuyos resultados se usan en este trabajo. Agradecemos a los árbitros que revisaron el trabajo, por sus aportes y sugerencias.

\section{REFERENCIAS}

ALFARO, A., MICHAUD, G. \& BIOLLEY, P., 1912: Informe sobre el terremoto de Toro Amarillo. Grecia.- Anales del Centro de Estudios Sismológicos de Costa Rica (1911).San José, Tipografía Nacional: 35-41.

ALVARADO, G.E., 1989: Los volcanes de Costa Rica.- 175 págs. EUNED, San José.

ALVARADO, G.E., MORALES, L.D., MONTERO, W., CLIMENT, A. \& ROJAS, W., 1988: Aspectos sismológicos y morfotectónicos en el extremo occidental de la Cordillera Volcánica Central de Costa Rica.- Rev. Geol. Amér. Central, 9: 75-98.

AMBRASEYS, N.N. \& ADAMS, R.D., 2001: The seismicity of Central America. A descriptive catalogue 1898-1995.- 309 págs. Imperial College Press, Londres.

ARIAS, O. \& DENYER, P., 1991: Estructura geológica de la región comprendida en las hojas topográficas Abra, Caraigres, Candelaria, Río Grande, Costa Rica.- Rev. Geol. Amér. Central, 12: 61-74.

ARIAS, O. \& DENYER, P., 1994: Compresión y dilatación norte-sur en el suroeste del Valle Central, Costa Rica.- Rev. Geol. Amér. Central, 17: 85-94.

ARROYO, I.G. \& ALVARADO, G.E., 2002: Evaluación neotectónica de la falla San Miguel y alrededores, enfocada en los pro- yectos hidroeléctricos Cariblanco y Toro III.- 25 págs. + mapa, ICE, San José [Inf. Interno].

ARREDONDO, S.G. \& SOTO, G.J., 2006: Edad de las lavas del Miembro Los Bambinos y sumario cronoestratigráfico de la Formación Barva, Costa Rica.- Rev. Geol. Amér. Central, 34-35: 59-71.

ATTWOOD, G., 1882: On the Geology of a part of Costa Rica.- Quart. J. Geol. Soc. London, 38: 328-336.

BARQUERO, R., 1995: Proyecto hidroeléctrico Laguna Hule. Estudio sismológico para la etapa de factibilidad. - 11 págs. OSV.95.09ICE, San José [Inf. Interno].

BARQUERO, R., BOSCHINI, I. \& ALVARADO, G.E., 2007: Estudio sismo-tectónico para el P.H. Toro 3.- 58 págs. ICE, San José [Inf. Interno].

BERGOEING, J.P. \& MALAVASSI, E., 1982: Geomorfología del Valle Central de Costa Rica (explicación de la carta geomorfológica 1:50 000).- 25 págs. IGN, San José.

BOHNENBERGER, H., 1968: A photogeological study of the western Central Valley, Costa Rica.- 20 págs. Min. Agric. Ganad. y Serv. Nac., Acueductos y Alcantarillados, San José.

BOHNENBERGER, H. \& MADRIGAL, R., 1968: Mapa fotogeológico de la cuenca del río Virilla y sus alrededores [1 hoja 1:50 000].- En: BOHNENBERGER, H.: A photogeological study of the western Central Valley, Costa Rica. Ministerio de Agricultura y Ganadería y Servicio Nacional de Acueductos y Alcantarillados.

BORGIA, A., BURR, J., MONTERO, W., MORALES, L.D. \& ALVARADO, G.E., 1990: Fault Propagation Folds Induced by Gravitacional Failure and Slumping of 
the Central Costa Rica Volcanic Range: Implications for Large Terrestrial and Martian Volcanic Edifices.- J. Geophys. Res. 95 (B9): 14357-14382.

BRENES, J., 2003: Geología y peligro volcánicos del Flanco Oeste y Suroeste del volcán Barva.- 115 págs. Univ. de Costa Rica, San José [Tesis Lic.].

BROWN, G.C., RYMER, H. \& THORPE, R.S., 1987: The evolution of andesite volcano structures: new evidence from gravity studies in Costa Rica.- Earth Planet. Sc. Let. 82: 323-334.

CAMPAÑA GEOLÓGICA, 2004: Estudio geológico en el cantón de Poás, provincia de Alajuela.- 168 págs. Univ. de Costa Rica, San José [Inf. Campaña Geol.].

CARR, M.J., SAGINOR, I., ALVARADO, G.E., BOLGE, L.L., LINDSAY, F.N., MILIDAKIS, K., TURRIN, B.D., FEIGENSON, M.D. \& SWISHER III, C.C., 2007: Element fluxes from the volcanic front of Nicaragua and Costa Rica.Geochem. Geophys. Geosyst. 8(6), DOI: 10.1029/2006GC001396.

DENYER, P., MONTERO, W. \& ALVARADO, G.E., 2003: Atlas tectónico de Costa Rica.81 págs. Ed. Univ. de Costa Rica.

DÓNDOLI, C. \& CHAVES, R., 1968: Mapa adjunto al estudio geológico del Valle Central.Escala 1:150 000, IGN, San José.

FERNÁNDEZ A., M. \& PACHECO, J., 1998: Sismotectónica de la región central de Costa Rica.- Rev. Geol. Amér. Central, 21: 5-23.

GAZEL, E. \& RUIZ, P., 2005: Los conos piroclásticos de Sabana Redonda: componente magmático enriquecido del volcán Poás, Costa Rica.- Rev. Geol. Amér. Central, 33: 45-60.
GONZÁLEZ, C., 1910: Temblores, terremotos, inundaciones y erupciones volcánicas en Costa Rica, 1608-1910.- 239 págs. Tipografía de Avelino Alsina, San José.

MARSHALL, J.S., FISHER, D.M. \& GARDNER, T.W., 2000: Central Costa Rica deformed belt: Kinematics of diffuse faulting across the western Panama block.- Tectonics, 19: 468-492.

MÉNDEZ, J., SOTO, G.J., ZAMORA, N., VARGAS, A., SJÖBOHM, L., BONILLA, E., BARAHONA, D., SOLÍS, L., KYCL, P. \& BAROŇ, I., 2009: Geología de los deslizamientos provocados por el Terremoto de Cinchona, Costa Rica (Mw 6,2; 8 de enero del 2009) en la Ruta 126 (Varablanca-San Miguel).- 22 págs. X Congreso Nacional de Geotecnia y V Encuentro Centroamericano de Geotecnistas. San José, Costa Rica, Memoria digital.

MONTERO, W., 1994a: Sismicidad y neotectónica. - En: DENYER, P. \& KUSSMAUL, S. (comps.): Atlas Geológico Gran Área Metropolitana.- Ed. Tecnol. Costa Rica: 147-160.

MONTERO, W., 1994b: Neotectonics and related stress distribution in a subduction-collisional zone: Costa Rica.- En: SEYFRIED, H. \& HELLMANN, W. (ed.): Geology of an evolving island arc, The Istmus of Southern Nicaragua, Costa Rica and Western Panamá.- Profil, 7: 125-141.

MONTERO, W., 2001: Neotectónica de la región central de Costa Rica: frontera oeste de la microplaca de Panamá.- Rev. Geol. Amér. Central, 24: 29-56.

MONTERO, W., 2003: El sistema de falla AtirroRío Sucio y la cuenca de tracción IrazúTurrialba: Indentación tectónica relacionada con la colisión del levantamiento del Coco.Rev. Geol. Amér. Central, 28: 5-29. 
MONTERO, W., MACHETTE, M.N., DENYER, P., BARQUERO, R., ALVARADO, G. \& COWAN. H., 1998: Map of Quaternary Faults and Folds in Costa Rica and its Offshore Regions.- 63 págs + mapa escala 1: 500 000. Open-File Report 98-481, U. S. Geol. Surv.

MONTERO, W. \& MORALES, L.D., 1990: Deformación y esfuerzos neotectónicos en Costa Rica.- Rev. Geol. Amér. Central, 11: 69-87.

MORALES, L. D., MONTERO, W. \& MADRIGAL, R., 1992: El terremoto de Fraijanes de 1888 y el sistema de fallas de Alajuela. Implicaciones del peligro sísmico potencial para el Valle Central Occidental.Rev. Geogr. Amér. Central, 25-26: 227240.

NORABUENA, E., DIXON, T., SCHWARTZ, S., DESHON, H., NEWMAN, A., PROTTI, M., GONZÁlEZ, V., DORMAN, L., FLUEH, E., LUNDGREN, P., POLLITZ, F., \& SAMPSON, D., 2004: Geodetic and seismic constraints on some seismogenic zone proceses in Costa Rica.- J. Geophys. Res. 109, DOI:10.1029/2003JB002931.

PERALDO, G. \& MONTERO, W., 1994: Temblores del período colonial de Costa Rica.- 162 págs. Ed. Tecnol. Costa Rica, Cartago.

PÉREZ, W., ALVARADO, G.E. \& GANS, P., 2006: The 322 ka Tiribí Tuff: stratigraphy, geochronology and mechanisms of deposition of the largest and most recent ignimbrite in the Central Valley, Costa Rica.Bul. Volcanol. 69: 25-40.

PROSSER, J.T. \& CARR, M.J., 1987: Poás volcano, Costa Rica: Geology of the summit region and spatial and temporal variations among the most recent lavas.- J. Volcanol. Geoth. Res. 33: 131-146.
ROMANES, J., 1912: Geology of a part of Costa Rica.- Quat. J. Geol. Soc. London, 68: 103139.

ROJAS, W., MONTERO, W., LÓPEZ, A., ALVARADO, G., VARGAS, A. \& TAYLOR, W., 2009: Tectónica, Proceso de Ruptura, Intensidades y Esfuerzos Locales (Cap. III).- En: RSN: ICE-UCR: Informe del terremoto de Cinchona del jueves 8 de enero de 2009.- Univ. de Costa Rica, San José: 26-44.

SAPPER, K., 1905: Gebirgsbau und Boden des südlichen Mittelamerika.- 82 págs. Justus Perthes, Gotha, 151.

SCHAUFELBERGER, P., 1935: Un estudio geológico de la Meseta Central Occidental.- Rev. Inst. Def. Café Costa Rica, 2: 1-15.

SOTO, G.J., 1990: Consideraciones volcanológicas y tectónicas preliminares del área de Laguna Hule.- 14 págs. Sección de Sismología e Ingeniería Sísmica, ICE [Inf. interno].

SOTO, G.J., 1999: Geología regional de la Hoja Poás (1:50 000).- En: ALVARADO, G.E. \& MADRIGAL, L.A. (eds.): Estudio GeológicoGeotécnico de Avance a la Factibilidad del P.H. Laguna Hule.- (más mapa geológico escala 1: 50 000), ICE, San José [Inf. interno]:15-45.

SOTO, G.J. (ed.), 2005: Geología del cantón de Poás y estudios adicionales.- 198 págs. FUNDEVI, Univ. de Costa Rica [Inf. interno].

SOTO, G.J. \& ALVARADO, G.E., 1989: Procesos volcánicos asociados con el agua subterránea. El caso de los volcanes Arenal y Poás, Costa Rica.- Mem. III Cong. Nac. Rec. Hídricos, San José: 249-261. 
SUPPE, J., 1985: Principles of Structural Geology.- 537 págs. Prentice-Hall Inc., Englewood Cliffs, Nueva Jersey.

THORPE, R.S. \& FRANCIS, P.W., 1981: Magma chamber below Poás Volcano, Costa Rica.J. Geol. Soc. London, 138: 367-373.

TWISS, R.J. \& MOORES, E.M., 1992: Structural Geology.- 532 págs. W.H. Freeman and Company, Nueva York.

VON FRANTZIUS, A., 1861: Beiträge zur Kenntniss der Vulkane Costa Ricas.Petermann's Mitt., 5: 329-338, 6: 381-385.

WILLIAMS, H., 1952: Volcanic history of the Meseta Central Occidental, Costa
Rica.- Univ. Calif. Pub. Geol. Sc. 29(4): 145-180.

WOODWARD-CLYDE CONSULTANTS, 1993: A preliminary evaluation of earthquake and volcanic hazards significant to the major population centers of the Valle Central, Costa Rica.- 71 págs +4 anexos y mapas. Ret Corporation [Inf. final].

ZIMMER, M.M., FISCHER, T.P., HILTON, D.R., ALVARADO, G.E., SHARP, Z.D. \& WALTER, J.A., 2004: Nitrogen systematics and gas fluxes of subduction zones: Insights from Costa Rica arc volatiles.- Geochem. Geophys. Geosystems, 5, Q05J11, DOI: 10.10209/2003GC000651. 